\title{
Rumen methanogens and mitigation of methane emission by anti-methanogenic compounds and substances
}

\author{
Amlan Patra ${ }^{1,2}$, Tansol Park', Minseok $\mathrm{Kim}^{3}$ and Zhongtang Yu ${ }^{1 *}$ (D)
}

\begin{abstract}
Methanogenic archaea reside primarily in the rumen and the lower segments of the intestines of ruminants, where they utilize the reducing equivalents derived from rumen fermentation to reduce carbon dioxide, formic acid, or methylamines to methane $\left(\mathrm{CH}_{4}\right)$. Research on methanogens in the rumen has attracted great interest in the last decade because $\mathrm{CH}_{4}$ emission from ruminants contributes to global greenhouse gas emission and represents a loss of feed energy. Some DNA-based phylogenetic studies have depicted a diverse and dynamic community of methanogens in the rumen. In the past decade, researchers have focused on elucidating the underpinning that determines and affects the diversity, composition, structure, and dynamics of methanogen community of the rumen. Concurrently, many researchers have attempted to develop and evaluate interventions to mitigate enteric $\mathrm{CH}_{4}$ emission. Although much work has been done using plant secondary metabolites, other approaches such as using nitrate and 3-nitrooxy propanol have also yielded promising results. Most of these antimethanogenic compounds or substances often show inconsistent results among studies and also lead to adverse effects on feed intake and digestion and other aspects of rumen fermentation when fed at doses high enough to achieve effective mitigation. This review provides a brief overview of the rumen methanogens and then an appraisal of most of the antimethanogenic compounds and substances that have been evaluated both in vitro and in vivo. Knowledge gaps and future research needs are also discussed with a focus on methanogens and methane mitigation.
\end{abstract}

Keywords: Anti-methanogenic compound, Methanogen, Mitigation, Protozoa, Rumen

\section{Background}

The unique environment (e.g., relatively rapid passage rate, readily available carbon dioxide $\left(\mathrm{CO}_{2}\right)$ and hydrogen $\left.\left(\mathrm{H}_{2}\right)\right)$ in the rumen helps assemble a community of archaea distinct to that of other anoxic habitats. Nearly all of these archaea are methanogens, most of which are hydrogenotrophic rather than acetoclastic methanogens even though ruminal acetate reaches high concentrations. Rumen methanogens scavenge $\mathrm{H}_{2}$ and $\mathrm{CO}_{2}$ produced by other fermentative members of the ruminal microbiome, producing $\mathrm{CH}_{4}$. Formic acid and methylamines produced by other rumen microbes are also available as substrates for rumen methanogens [1]. Therefore, methanogens interact with other ruminal

\footnotetext{
*Correspondence: yu.226@osu.edu

'Department of Animal Sciences, The Ohio State University, 2029 Fyffe Road, Columbus, $\mathrm{OH} 43210$, USA

Full list of author information is available at the end of the article
}

microbes, including protozoa [2], bacteria [3], and fungi [4], through interspecies $\mathrm{H}_{2}$ transfer. Overall, such interaction benefits the rumen fermentation as it prevents $\mathrm{H}_{2}$ accumulation and feedback inhibition. Most of the methanogens live freely in rumen liquid or as members of the biofilm adhering to feed particles, whereas a small portion of the ruminal methanogens are symbionts, either ectosymbionts or endosymbionts [5]. In cocultures, a hydrogenotrophic methanogen shifts fermentation towards acetate, increasing ATP yield and growth of cellulolytic bacteria [6]. In vivo studies also showed that inhibition of methanogens decreases acetate: propionate ratio, reflecting a shift of fermentation towards more reduced volatile fatty acids (VFA) than towards acetate [7-9]. Rumen $\mathrm{CH}_{4}$ emission accounts for about $17 \%$ of the global $\mathrm{CH}_{4}$ emission [10]. About $2-12 \%$ of the ingested feed energy is also lost as $\mathrm{CH}_{4}$ [11]. Therefore, ruminal methanogens have attracted much research 
interest in the past decade with an aim to understand their diversity and community structure, relationship with other ruminal microbes and with feed efficiency, $\mathrm{CH}_{4}$ emission, and responses to dietary interventions that were intended to mitigate ruminal $\mathrm{CH}_{4}$ emission. Enabled by comprehensive analysis using next generation sequencing (NGS) technologies, new information in the aforementioned aspects has been learned, but contradicting results are also reported, and critical gaps in our knowledge remain. Here we review the current understanding of ruminal methanogens, with an emphasis on protozoa-associated methanogens (PAM) and the responses of ruminal methanogens to anti- $\mathrm{CH}_{4} \mathrm{com}$ pounds and substances. Future research needs are also discussed.

\section{Overview of methanogens present in the rumen}

The diversity of the rumen methanogens is much smaller, and their diversity is much lower than that of rumen bacteria, with archaeal SSU rRNA only accounting for $6.8 \%$ of rumen total SSU rRNA [12]. Archaea in the rumen is represented by $<3.3 \%$ of the total rRNA (both $16 \mathrm{~S}$ and $18 \mathrm{~S}$ ) therein. Only eight species of ruminal methanogens have been isolated into pure cultures: Methanobacterium formicicum, Methanobacterium bryantii, Methanobrevibacter ruminantium, Methanobrevibacter millerae, Methanobrevibacter olleyae, Methanomicrobium mobile, Methanoculleus olentangyi, and Methanosarcina barkeri [13]. Recently, five new species were isolated, including Methanobrevibacter boviskoreani (isolated from the rumen of Korean native cattle) [14], Methanobacterium beijingense (isolated from the rumen of goat), Methanoculleus marisnigri (isolated from the rumen of Indian crossbred cattle), Methanoculleus bourgensis (isolated from the rumen of Holstein cattle), and Methanosarcina mazei (isolated from the rumen of Korean Hanwoo cattle) (based on the RDP database). One Thermoplasmatales-like pyrrolysine-dependent archaeon BRNA1 was isolated from bovine (GenBank access number: CP002916). Collectively, 16S rRNA gene sequences from cultured methanogens only accounted for approximately $0.7 \%$ of the total archaeal sequences of rumen origin, and several taxa do not have a single cultured representative (Fig. 1). Most of the isolates are members of the family Methanobacteriaceae. Compared to other anaerobic habitats where $>100$ species of methanogens of 28 genera have been isolated, the diversity and species richness of ruminal methanogens are quite low, reflecting the highly selective ruminal environment for methanogens. In addition, sequenced ruminal $16 \mathrm{~S}$ rRNA gene clones shared $>95 \%$ sequence similarity with that of Methanobrevibacter gottschalkii, Methanobrevibacter thaueri, Methanobrevibacter smithii and Methanosphaera stadtmanae [15, 16], indicating that these species may be common ruminal methanogens.

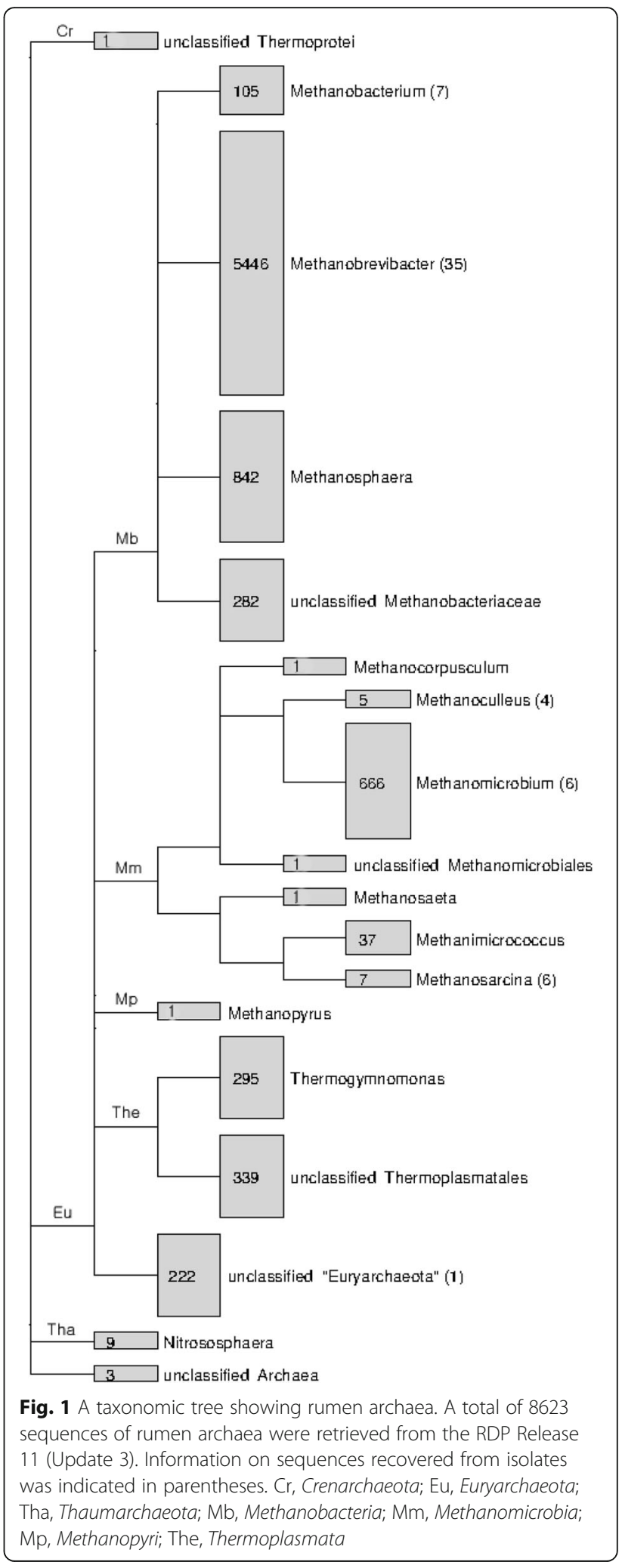

Much of the ruminal methanogen diversity was characterized by $16 \mathrm{~S}$ rRNA gene sequences. The RDP Release 11 (Update 3) contains 8623 archaeal 16S 
rRNA gene sequences of rumen origin. These sequences were generated using the Sanger sequencing technology, which produces higher sequence accuracy than NGS technologies, in 96 separate studies including 48 unpublished studies. About $90 \%$ of these sequences were assigned to methanogens (Fig. 1). These sequences were classified to 10 known genera, with Methanobrevibacter being represented by $63.2 \%$ of all the sequences followed by Methanosphaera (9.8\%), Methanomicrobium (7.7\%), and Methanobacterium (1.2\%). It should be noted that Methanocorpusculum and Methanosaeta were each represented by only one sequence. These two genera of methanogens are probably not residents of the rumen. The order Thermoplasmatales, which was previously referred to as the rumen cluster $\mathrm{C}$ (RCC) group, is represented by $7.4 \%$ of the total archaeal sequences. One apparent discrepancy is the good representation of cultured species of Methanobacterium and relatively small proportion of sequences classified to this genus. The opposite holds true for the genus Methanosphaera. Understanding such discrepancies and isolation and characterization of Thermoplasmatales-like methanogens will help further advance the microbial biology of rumen methanogens.

\section{Free-living ruminal methanogens}

Most of the methanogens are not associated with ruminal protozoa or fungi [17], which is reflected by the smaller number of $16 \mathrm{~S}$ rRNA gene sequences recovered from protozoa than from rumen content or fluid (461 vs. $816216 \mathrm{~S}$ archaeal rRNA gene sequences archived in RDP). It should be noted that this result could also arise from the difficulty associated with obtaining archaeal DNA from protozoal cells. No sequence assigned to Methanobacterium has been recovered from rumen protozoa, leading to speculation that species of Methanobacterium are probably not PAM. In contrast, a significant portion (32.8\%) of the Methanobrevibacter sequences archived in RDP was recovered from protozoa. Methanosphaera was also thought to be free-living. However, considering that Methanobrevibacter accounts for at least $65 \%$ of the rumen methanogens, the significant portion of the Methanobrevibacter sequences recovered from rumen protozoa may simply reflect the probability of sequence recovery, rather than a selective association between rumen protozoa and Methanobrevibacter. It should be noted that the majority of "free-living" methanogens are actually integrated into the biofilm on the surface of feed particles where $\mathrm{H}_{2}$-producing bacteria actively produce $\mathrm{H}_{2}$ [18]. Being protected by the biofilm, these methanogens may not be inhibited as much as the free-living peers by anti-methanogenic inhibitors.

\section{Methanogens associated with rumen protozoa}

Most species of the rumen ciliate protozoa contain hydrogenosomes, a unique type of membrane-bounded organelles producing $\mathrm{H}_{2}$ by malate oxidization [19]. These organelles can attract some methanogens as endosymbionts [13]. Hydrogen generated by rumen protozoa could be utilized by PAM, which benefits both parties [20]. Methanogens have been observed internally [21] and externally $[2,22]$. Through feeding or fasting of sheep and by flushing the sheep rumen with $\mathrm{N}_{2}$ or $\mathrm{H}_{2}$ gas, Stumm et al. [23] showed that the frequency of methanogens associated ectosymbiotically was affected by the relative contribution of $\mathrm{H}_{2}$ production by rumen ciliates and $\mathrm{H}_{2}$-producing bacteria. This is expected, but it remains to be determined if the species of methanogens associated endosymbiotically with rumen ciliates can also be affected. Based on fluorescence in situ hybridization (FISH) analysis, about $16 \%$ of the rumen ciliates contained methanogens inside their cells [24]. A possible explanation for the low incidence is that the intracellular association may be transient rather than permanent. However, early studies indicated that rumen ciliates do not have endosymbiotic methanogens though they might have ectosymbiotic methanogens $[19,25,26]$. The difficulty in distinguishing engulfed methanogens from true endosymbiotic methanogens presents a challenge to determining if rumen ciliates possess true endosymbiotic methanogens and bacteria.

Some studies have attempted to identify PAM (Table 1). Because of the labor-intensive procedures involved, PAM are mostly identified using DNA-based methods, and only one strain of methanogen (isolates MB-9; related to Methanobrevibacter ruminantium) has been reported to be associated with a ciliate fraction of the rumen of sheep [27]. Among the methanogen sequences of rumen origin archived in the RDP database (Release 11, Update 3), only a very small proportion (5.3\%) was recovered from washed protozoa cells. These sequences were derived from a limited number of studies [28-33]. Methanobrevibacter and Methanomicrobium were the first and the second largest genera reported to be PAM, and they accounted for $32.8 \%$ and $23.0 \%$ of the total PAM sequences, respectively. Methanomicrobium is better represented in the PAM sequences $(23.0 \%)$ than in the total archaeal sequences (7.7\%), so is Thermoplasmatales $(22.1 \%$ vs. $7.4 \%)$. Species of both taxa may be among the predominant PAM. It should be cautioned that the above results may be biased because only a small number of PAM sequences were obtained from selected protozoa [13]. Besides, the PAM sequences may be contaminated with sequences of non-PAM. Therefore, future studies are needed to characterize PAM using methods that can eliminate possible contamination with non-PAM. 


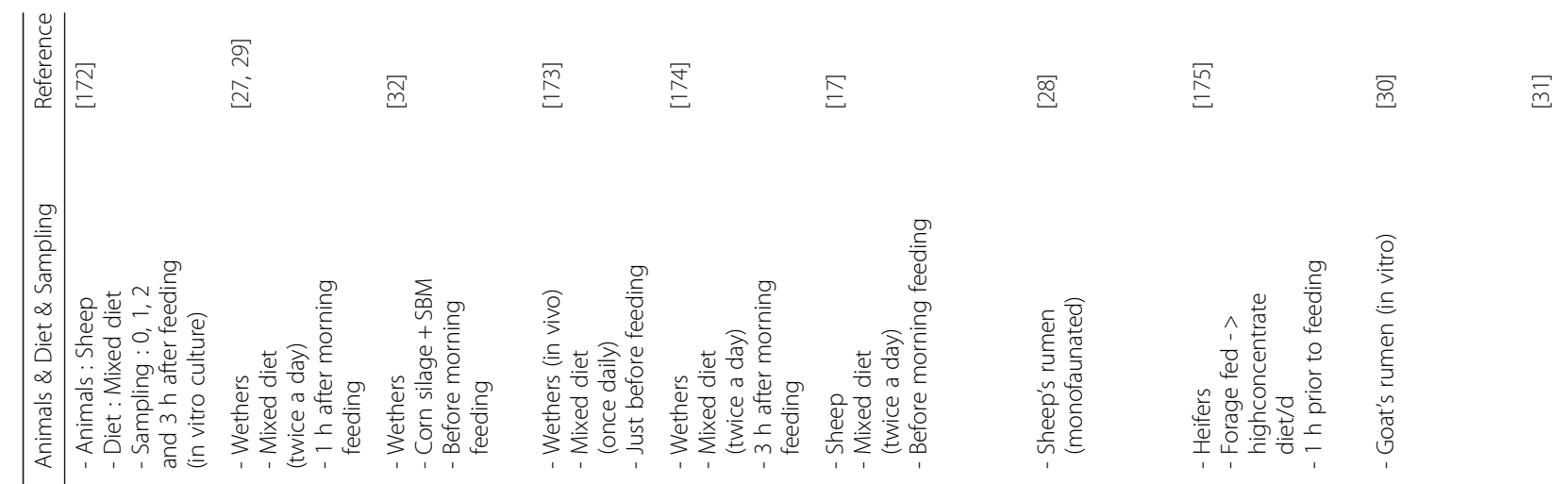

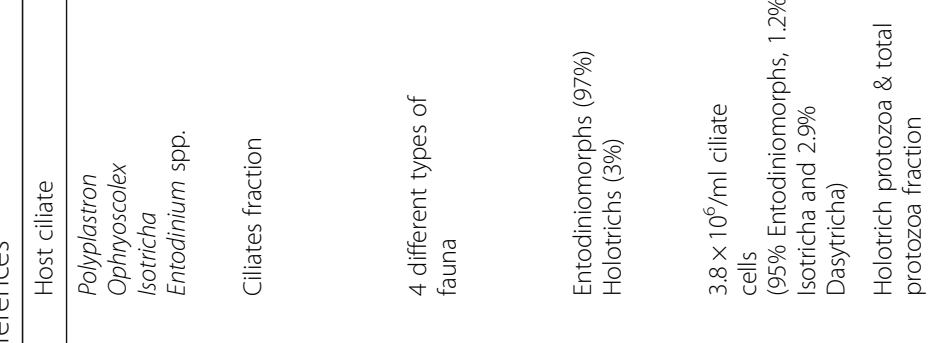

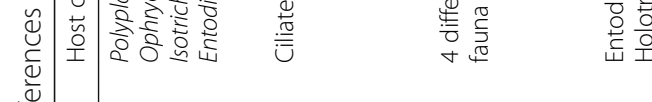

\section{$\stackrel{\oplus}{ \pm}$}

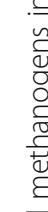

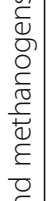

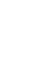

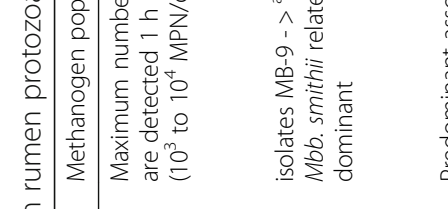

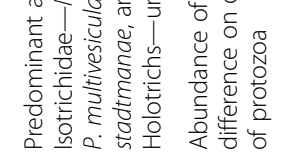

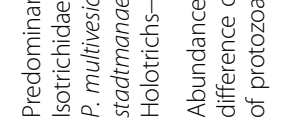
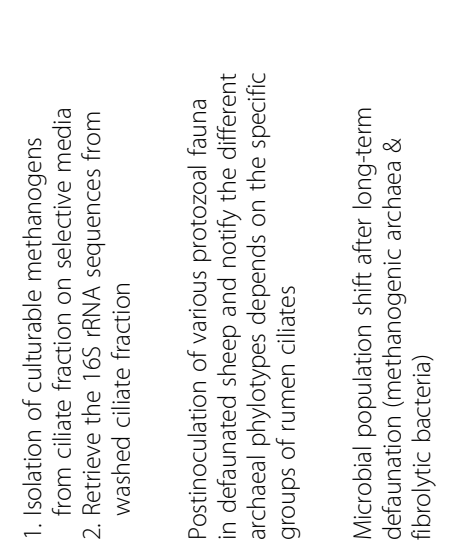
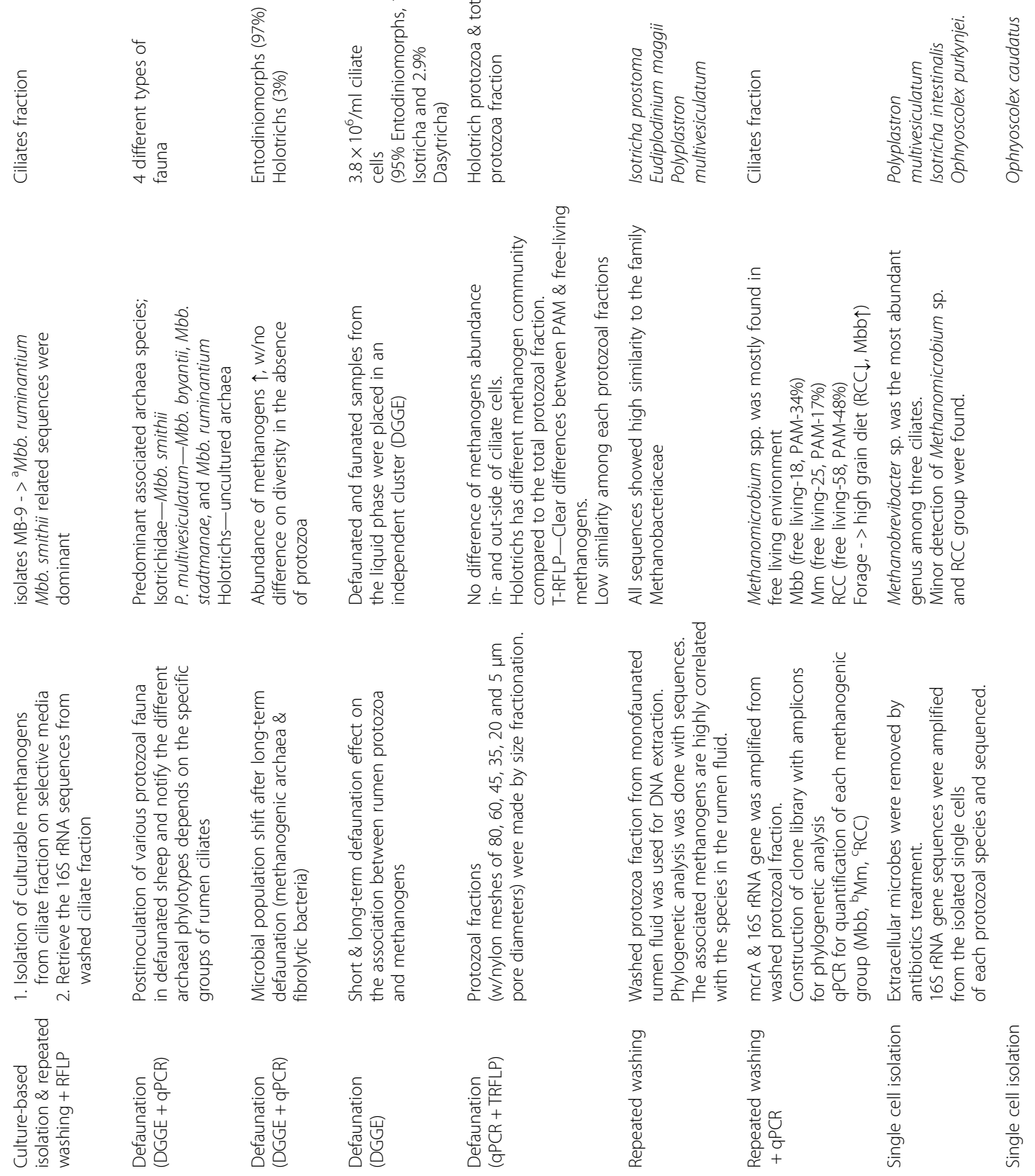
Petra et al. Journal of Animal Science and Biotechnology (2017) 8:13

Page 5 of 18

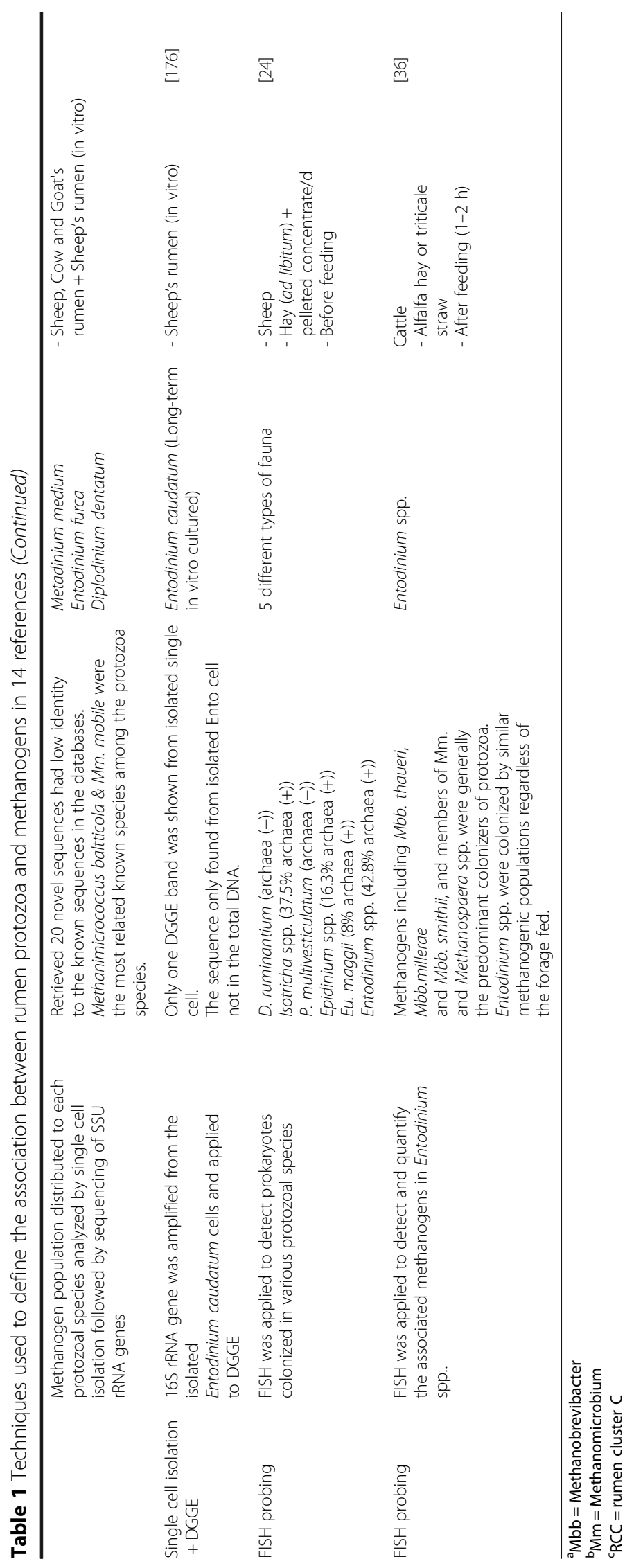


One T-RFLP analysis showed that ruminal protozoa have similar density of methanogens as rumen fluid [17]. Because T-RFLP is not a quantitative method, qPCR will be required to improve the estimate. Early studies based on comparisons in methanogen diversity between faunated and defaunated rumen suggest the impact of rumen protozoa on methanogen diversity and population dynamics [32, 34, 35], but that differences cannot be solely attributed to the PAM. From a sequence-based analysis of washed protozoal cells, different archaeal phylotypes were found to be associated with specific species or genera of protozoa, but discrepancies arose from different studies (Fig. 2). A recent study using FISH, however, showed similar composition and relative abundance of methanogens colonizing ciliates related to

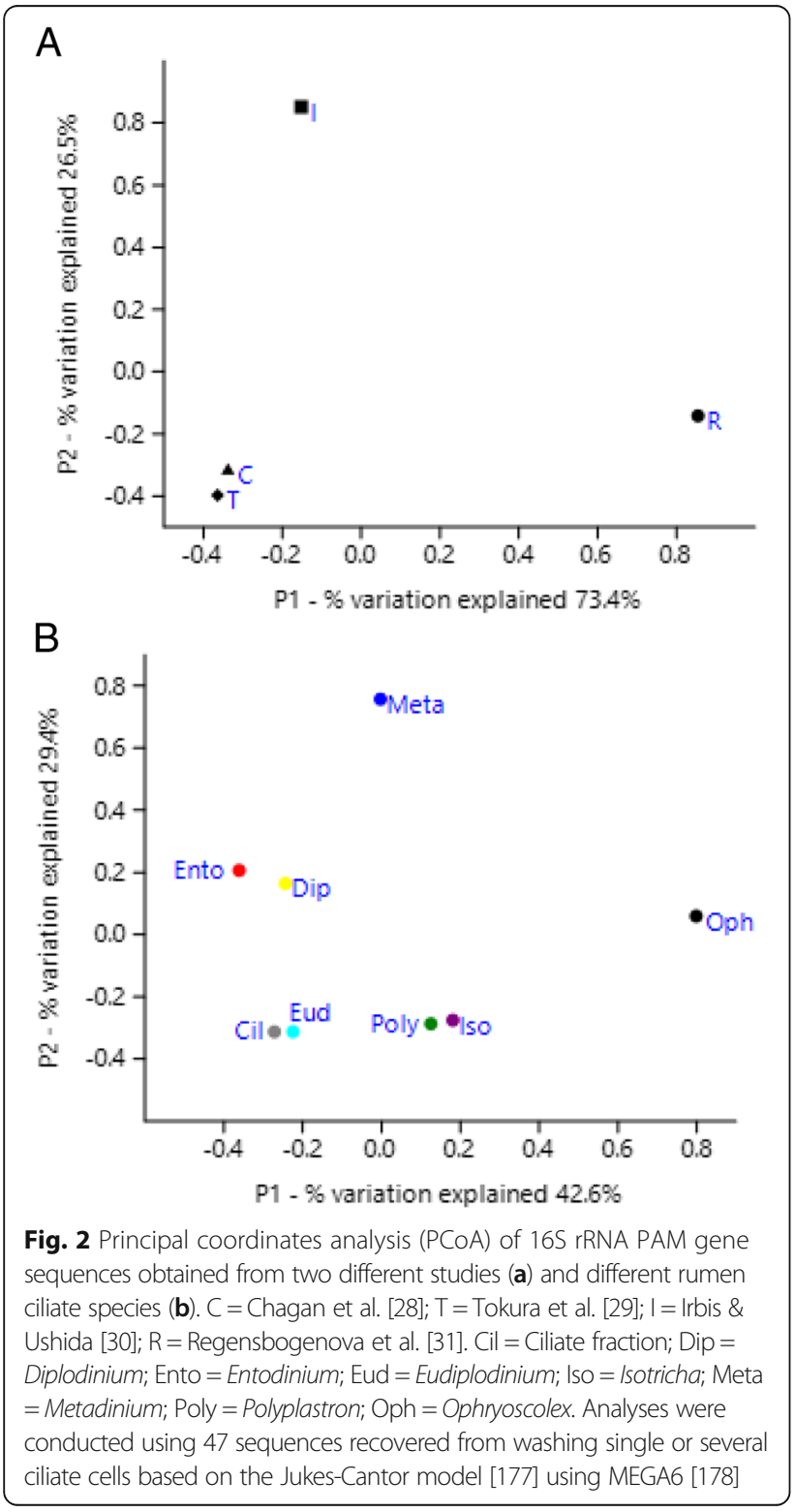

Entodinium simplex, E. caudatum, and E. furca [36]. Rumen ciliates were thought to select their prey (primarily bacteria and methanogens) [26, 37], but a recent in vitro study using single species of ruminal protozoa $(E$. caudatum, Diplodinium dentatum, and Metadinium medium) and ruminal bacteria (Ruminococcus albus and Streptococcus bovis) showed no selective predation [38]. Conflicting results among studies reflect the difficulties in analysis of true PAM. Selective association between rumen ciliates and methanogens is a fascinating theory. Conceivably, some of the engulfed bacteria and methanogens can escape digestion from the food vacuoles and establish themselves as endosymbionts. It is not known, however, what attributes allow certain methanogens to establish themselves as endosymbionts. Single cell genomics will provide opportunities to further identify PAM and the processes by which PAM is established. Axenic cultures of rumen ciliates will ultimately provide the unequivocal evidence of PAM and help elucidate the mechanisms underpinning their endosymbiosis. However, no axenic culture of rumen ciliates has been achieved despite repeated efforts, suggesting the necessity of a symbiotic relationship with prokaryotes for the long-term survival of ruminal ciliates.

\section{Interaction of methanogens with other rumen microbes}

Some rumen methanogens can also become associated with fungi, but little is known about fungi-associated methanogens (FAM). An early study suggests that rumen fungi do not have endosymbiotic methanogens although they may have ectosymbiotic methanogens [39]. In a recent study, species of Methanobrevibacter were detected by PCR in cultures of Piromyces, Anaeromyces, and Neocallimastix [40]. Methanogens were also detected in some rumen fungal cultures, but it was not reported if the methanogens and fungi had any physical association, either ectosymbiotic or endosymbiotic [41, 42]. All rumen fungi contain hydrogenosomes $[19,43]$, but definitive evidence is needed to determine if rumen fungi carry true endosymbiotic methanogens.

No symbiotic association between rumen bacteria and methanogens is expected, but the integration of methanogens into bacterial biofilms on feed particles in itself represents a form of interaction, and most fermentative ruminal bacteria produce $\mathrm{CO}_{2}$ and $\mathrm{H}_{2}$, which are the substrates for methanogens [44]. Thus, rumen bacteria and methanogens interact mutualistically through interspecies $\mathrm{H}_{2}$ transfer. Such interspecies $\mathrm{H}_{2}$ transfer was demonstrated in co-cultures of methanogens with Ruminococcus albus [45], R. flavefaciens [46], and Selenomonas ruminantium [47]. The interaction between rumen bacteria and methanogens affects energy conservation, VFA profiles, and $\mathrm{CH}_{4}$ 
production by the rumen microbiome. More studies are required to investigate microbial interaction at microbiome level. Metagenomic and metatranscriptomic analysis can help determine co-occurrence patterns, which can shine new light on bacteria-methanogen interaction at microbiome level.

\section{Effects of anti-methanogenic compounds on rumen methanogens}

Numerous $\mathrm{CH}_{4}$ mitigation technologies have been explored, including interventions of animal management, dietary composition, rumen fermentation, and methanogens $[10,48,49]$. Among these mitigation options, inhibiting the growth or the metabolic activity of methanogens is the most effective approach. Another strategy is to modulate rumen microbiome so that fermentation is shifted toward decreased $\mathrm{H}_{2}$ production and increased production of reduced VFA (e.g., propionate). Even though many studies have been reported in the literature, substantial discrepancies exist among different studies concerning the magnitude of efficacy and adverse impact on feed digestion and fermentation. Here we review the antimethanogenic compounds evaluated with a focus on their impact rumen methanogens.

\section{Coenzyme $M$ analogs}

Methyl-CoM reductase (Mcr) mediates the final step of all the methanogenesis pathways and CoM (2-mercaptoethanesulfonic acid) is an essential cofactor serving as the methyl group carrier. Mcr reduces methyl-CoM to $\mathrm{CH}_{4}$. CoM is found in all known methanogens but not in other archaea or bacteria [50]. Several halogenated sulfonated compounds, including 2-bromoethanesulfonate (BES), 2-chloroethanesul fonate (CES), and 3-bromopropanesulfonate (BPS), are structural analogs of CoM, and they can competitively and specifically inhibit Mcr activity, lowering $\mathrm{CH}_{4}$ production at relatively low concentrations [51]. Different species of methanogens vary in sensitivity to these inhibitors. Of three species tested on BES, Mbb. ruminantium was the most sensitive, while Methanosarcina mazei was the least sensitive, with Methanomicrobium mobile being intermediate [52]. All three species appeared to be resistant to BPS up to $250 \mu \mathrm{mol} / \mathrm{L}$ in pure cultures [52]. The different sensitivity to these CoM analogs has been attributed to varying ability to uptake these inhibitors into the cells $[53,54]$. Methanogens able to synthesize their own CoM are less dependent on external CoM and are thus less sensitive. Mbb. ruminantium is the only ruminal methanogen that requires CoM synthesized by other methanogens [55]. Some methanogens can become adapted to BES [52], suggesting that administration of BES could increase growth and persistence of BESresistant methanogens [56], which is consistent with the limited efficacy of BES in lowering $\mathrm{CH}_{4}$ production by rumen microbiome [57]. Thus, halogenated sulfonated compounds probably have limited application to mitigate $\mathrm{CH}_{4}$ production at the farm level.

\section{Halogenated aliphatic $C_{1}-C_{2}$ hydrocarbon}

Halogenated aliphatic compounds with 1 or 2 carbons, such as chloroform, bromochloromethane (BCM), bromoform, bromodichloromethane, dibromochloromethane, carbon tetrachloride, trichloroacetamide, and trichloroethyladipate, can lower ruminal $\mathrm{CH}_{4}$ production [48]. These halogenated compounds block the function of corrinoid enzymes and inhibit cobamide-dependent methyl group transfer in methanogenesis [58]. These halogenated compounds also competitively inhibit $\mathrm{CH}_{4}$ production by serving as terminal electron $\left(\mathrm{e}^{-}\right)$acceptors [59]. Drenching chloroform to cattle inhibited methanogenesis substantially for up to 32 days without affecting feed digestion or basic rumen function, but thereafter the inhibition faded away [60]. The population of RCC increased with time and $M b b$. ruminantium-related methanogens tended to become more prevalent later in the recovery phase, but methanogen diversity decreased [60]. The addition of BCM depressed $\mathrm{CH}_{4}$ production both in vitro [61] and in vivo $[62,63]$. In steers fed grain-based diets, BCM decreased $\mathrm{CH}_{4}$ production by 50 to $60 \%$ with no signs of toxicity or residues in meat [62]. Goel et al. [61] reported that the abundance of total bacteria and protozoa was not changed, but methanogenesis and growth of methanogens were drastically inhibited by BCM in both batch cultures and continuous fermenters. In contrast, BCM did not reduce the abundance of bacteria, protozoa, or methanogens in goats over 57 days although $\mathrm{CH}_{4}$ production decreased by $33 \%$ [63]. However, the archaeal community structure was altered [63] probably due to adaptation to BCM and/or selection of BCM-resistant methanogens. Therefore, halogenated aliphatic hydrocarbons have a limited utility to mitigate $\mathrm{CH}_{4}$ emission at farms. For example, they can deplete ozone and thus they are banned from commercial use in many countries. Chloroform is also a recognized carcinogen. Also, chloroform inhibits homoacetogenic bacteria and acetate-consuming sulfatereducing bacteria [64]. Although these two groups of bacteria do not have a major role under normal dietary conditions, homoacetogenic bacteria may become important when methanogens are inhibited. Nevertheless, halogenated aliphatic hydrocarbons are not likely to be used on farms to mitigate $\mathrm{CH}_{4}$ mitigation because regulatory hurdles will be encountered when these compounds are registered for commercial use.

Some marine plants such as red seaweed, and algae, lichen, and fungi can contain high concentrations of organobromine compounds such as bromomethane and bromoform [65]. A recent in vitro study showed that red seaweed Asparagopsis taxiformis lowered $\mathrm{CH}_{4}$ production by $99 \%$ at a dose of $2 \%$ of organic matter substrate [66]. 
No adverse effect on feed digestion or fermentation was noted at $\leq 5 \%$ (of dry matter) inclusion. Thus, red seaweed, and probably other organobromine-rich plants, may offer a potentially practical natural approach to mitigate $\mathrm{CH}_{4}$ emission. In vivo studies are required to determine optimum doses and to evaluate the effect on rumen microbiome, feed fermentation, as well as possible toxic effects. Moreover, large-scale production and transportation of these products to mitigate enteric methane emissions globally will also present a challenge.

\section{Nitrooxy compounds}

3-Nitrooxypropanol (3NOP) and ethyl-3NOP, two new synthetic compounds, have been shown to have specific anti-methanogenic properties. 3NOP appears to inactive Mcr by competitively binding to the Mcr active site and then oxidizing the $\mathrm{Ni}^{1+}$ that is required for Mcr activity [67]. The efficacy of $3 \mathrm{NOP}$ in lowering $\mathrm{CH}_{4}$ production varies considerably. Feeding of $3 \mathrm{NOP}$ at a dose rate of $2.5 \mathrm{~g} /$ day/cow mixed in diets decreased $\mathrm{CH}_{4}$ emission by $60 \%$ per $\mathrm{kg}$ of DM intake [68]. In a study using beef cattle, $3 \mathrm{NOP}$ fed at $2.0 \mathrm{~g} /$ day/cow decreased $\mathrm{CH}_{4}$ yield by $59 \%$, and the inhibition persisted for up to 112 days without much effect on feed intake, nutrient digestibility or total VFA concentrations [69]. In one recent study [9], $3 \mathrm{NOP}$ fed at $40-80 \mathrm{mg} / \mathrm{kg}$ feed DM in dairy cows decreased $\mathrm{CH}_{4}$ production by about $30 \%$ persistently for up to 84 days. Similarly, 3NOP fed at $2.5 \mathrm{~g} /$ day/cow decreased $\mathrm{CH}_{4}$ yield by $37 \%$ in dairy cows [70]. In sheep, $3 \mathrm{NOP}$ at $0.5 \mathrm{~g} /$ day also decreased $\mathrm{CH}_{4}$ production by $29 \%$ without adverse effect on digestion or rumen fermentation [71]. However, when 3NOP was directly added to the rumen through rumen cannula at a daily dose of 0.50 or $2.5 \mathrm{~g}$ per cow (equivalent to 25 to $125 \mathrm{mg} / \mathrm{kg}$ feed dry matter), the degree of $\mathrm{CH}_{4}$ suppression declined to $7-10 \%$ [72]. The later study suggests that $3 \mathrm{NOP}$ needs to be fed together with the diet to achieve efficacy. It seems that $3 \mathrm{NOP}$ could be used to lower $\mathrm{CH}_{4}$ emission from cows and sheep without adverse effects on nutrient utilization or animal performance. Only one study examined the effect of 3NOP on rumen methanogens, and it showed that $3 \mathrm{NOP}$ decreased methanogen abundance while increasing that of protozoa [69]. Future studies are warranted to investigate how 3NOP affects methanogens and other rumen microbes.

\section{Pterin compounds}

Pterin is a group of structural analogs of deazaflavin $\left(\mathrm{F}_{420}\right)$, which is a coenzyme involved in two steps of the hydrogenotrophic methanogenesis pathway [73]. Therefore, pterin compounds can competitively inhibit $\mathrm{CH}_{4}$ production. In one study, $\mathrm{CH}_{4}$ production by $M b b$. ruminantium, Ms. mazei, and Mm. mobile was significantly decreased by lumazin (2,4-pteridinedione) in a dose-dependent manner from 0.06 to $0.24 \mathrm{mmol} / \mathrm{L}$ [52] As expected, pterin is much less efficacious in mixed rumen cultures than in pure methanogen cultures [52]. It was suggested that lumazine could be degraded or transformed by some microbes in mixed cultures or adsorbed to solid particles where it becomes unavailable to methanogens. Some N-substituted derivatives of $p$-aminobenzoic acid, which are inhibitors of methanopterin synthesis in methanogens, decreased methanogenesis in ruminal cultures without inhibiting VFA production [74]. Mbb. ruminantium appeared to be able to adapt to low concentrations of this pterin compound over time, while Ms. mazei and Mm. mobile could not. Apparently, methanogens vary in susceptibility to pterin. It remains to be shown if pterin affects the diversity of methanogens and other rumen microbes.

\section{Hydroxymethylglutaryl-CoA (HMG-S-CoA) reductase inhibitors}

All archaea contain long-chain isoprenoid alcohols as the major component of their cell membrane [75]. Isoprenoid alcohols are unique to archaea. They are synthesized from mevalonate that is formed by reduction of 3hydroxy-3-methylglutaryl coenzyme A (HMG-S-CoA) catalyzed by HMG-S-CoA reductase. This enzyme is also used for the synthesis of the same precursor ultimately used in cholesterol synthesis in humans. As an inhibitor of HMG-S-CoA reductase, statins can inhibit the growth of methanogens by inhibiting the synthesis of mevalonate [76]. Lovastatin and mevastatin may also act as a potential inhibitor of $\mathrm{F}_{420}$-dependent NADP oxidoreductase as shown in the model structure of that enzyme [77]. In the earliest reported study, mevastatin at $5.6 \mu \mathrm{mol} / \mathrm{L}$ inhibited the growth of all three strains of rumen Methanobrevibacter, but not rumen bacteria in vitro [78]. In studies using a rumen simulation technique (Rusitec), lovastatin $(150 \mathrm{mg} / \mathrm{L})$ reduced $\mathrm{CH}_{4}$ production by approximately $42 \%$ without altering bacterial counts or nutrient fermentation [79]. Statins (e.g., lovastatin and mevastatin) are expensive prescription drugs to lower cholesterol in humans [80]. The high cost makes statins cost-prohibitive as anti-methanogenic inhibitors.

The high cost of pure statins promoted a search for natural sources of statins as agents to mitigate $\mathrm{CH}_{4}$ production. Lovastatin is a secondary metabolite of idiophase of several fungal species (e.g., Penicillium spp., Aspergillus terreus, Monascus purpureus, and Pleurotus ostreatus), and it can reach a concentration up to $2.8 \%$ of the dry weight of $P$. ostreatus (oyster mushrooms) [81] and $261 \mathrm{mg} / \mathrm{kg}$ fermented rice straw [82]. Lovastatin extracted from fermented rice straw significantly reduced total $\mathrm{CH}_{4}$ production by rumen methanogens by nearly $28 \%$ after $48 \mathrm{~h}$ in vitro incubation [82]. Extract from $A$. terreus-fermented rice straw containing lovastatin 
(97 mg/g dry mass) also significantly reduced $\mathrm{CH}_{4}$ production and abundance of methanogens, especially Methanobacteriales, and aerobic fungi, but increased several fiber-degrading bacteria [82]. Lovastatin also altered the morphology of $M$. smithii significantly, resulting in abnormal membrane formation and asymmetric cell divisions and increased HMG-S-CoA reductase gene expression [83]. Fermented rice straw extract also modulated expression of several genes associated with methanogenesis, increasing expression of $m t r, m t a$, and $m c r$ while decreasing expression of hmd and fno [83]. Supernatant fractions containing statins produced by Mortierella wolfii also appeared promising to inhibit methanogenesis without reducing overall fermentation [84]. In another study using sheep, fermented rice straw containing metabolites (possibly pravastatin and mevastatin) produced by Monascus spp. decreased $\mathrm{CH}_{4}$ emission (by 30\%), the abundance of methanogens, and ruminal acetate: propionate ratio compared with the unfermented rice straw [85]. If these fungi could be grown on low-quality forages such as straws, they can be used to decrease $\mathrm{CH}_{4}$ production in ruminants. However, many fungi produce mycotoxins, which must be avoided for the practical feeding of animals [86].

Diallyl disulfide, the main ingredient of garlic oil, is known to inhibit HMG-S-CoA reductase [87]. Garlic oil $(300 \mathrm{mg} / \mathrm{L})$ was more effective than lovastatin as an inhibitor of $\mathrm{CH}_{4}$ production (by up to $91 \%$ reduction); however, garlic oil also inhibited bacterial growth, which likely reduces the availability of methanogenesis substrates [79]. Garlic oil lowered $\mathrm{CH}_{4}$ production in vitro and growth of methanogens, altered community structure of methanogens after $24 \mathrm{~h}$ incubation [7, 8]. Moreover, interestingly, the anti-methanogenic efficacy increased over time up to 18 days of incubation [88]. Few studies have tested garlic oil in vivo. In one study using sheep, neither diallyl disulfide nor lovastatin decreased $\mathrm{CH}_{4}$ emission per animal, but both treatments modestly reduced $\mathrm{CH}_{4}$ produced per $\mathrm{g}$ of dietary fiber consumed [89]. Feeding of garlic or its metabolites may influence the flavor of meat and milk from ruminants [90].

\section{Anti-methanogen vaccines}

Upon vaccination, anti-methanogen antibodies were found in the serum of vaccinated sheep [91]. The first two anti-methanogen vaccines were prepared from whole cells of three and seven selected methanogens in Australia, and these vaccines resulted in no or minimal (only $8 \%$ compared to control) decrease in $\mathrm{CH}_{4}$ emission [92]. The inefficacy was attributed to the small numbers of methanogen species that the vaccines could target. However, methanogen abundance or $\mathrm{CH}_{4}$ production was not decreased by vaccination using a vaccine that was based on a mixture of five methanogen species representing $>52 \%$ of the rumen methanogen populations, though the composition of methanogens was altered [93]. It was suggested that anti-methanogen vaccines should be developed based on cell surface proteins that are conserved among rumen methanogens to achieve effective results [94]. It should be noted that most antibodies circulate in the blood of a host, and only a tiny amount can enter the rumen through saliva. The amount of antibodies entering the rumen is probably too small to have any effect. Also, antibodies entering the rumen can be rapidly degraded by proteolytic bacteria therein. It stands to reason that vaccination may not be a feasible approach to mitigate $\mathrm{CH}_{4}$ emission from livestock.

\section{Fats and fatty acids}

Feeding fat to ruminants lowers $\mathrm{CH}_{4}$ emissions [95, 96]. Based on a meta-analysis, fat supplementation reduced $\mathrm{CH}_{4}$ by $3.77 \%$ in cattle and $4.30 \%$ in sheep per $1 \%$ dietary fats $[97,98]$. Fat decreases $\mathrm{CH}_{4}$ production (expressed as $\mathrm{g} / \mathrm{kg}$ digestible DM) more from sheep than from cattle, which was attributed to the comparatively lower depression of DM digestion together with numerically larger depression of $\mathrm{CH}_{4}$ production $(\mathrm{g} / \mathrm{kg} \mathrm{DM})$ by fat in sheep [98]. Among fatty acids, C12:0, C18:3 and other polyunsaturated fatty acids (PUFA) are more potent than saturated fatty acids $[97,99]$. The $\mathrm{CH}_{4}$-suppressing efficacy of fats generally persists [97], with persistent suppression being noted for 72 days and longer $[100,101]$ in cattle.

Fats supplemented up to $6 \%$ of the diet (DM) can also improve milk production while appreciably decreasing $\mathrm{CH}_{4}$ emissions (15\%) in cattle, but higher concentrations decreased production efficiency due to a reduction of feed digestion and fermentation [97]. Medium-chain fatty acids (MCFA) and PUFA can lower abundance and metabolic activities of rumen methanogens and change their species composition $[95,99,102]$. PUFA can also directly inhibit protozoa and serve as hydrogen sink through biohydrogenation [103]. Both MCFA and PUFA appear to damage the cell membrane, thereby abolishing the selective permeability of cell membrane, which is required for survival and growth of methanogens and other microbes [104]. The inhibitory effect of fat on methanogenesis is more pronounced in cattle fed concentrate-based diets than in cattle fed forage-based diets [97]. Because C12: and C14:0 is more inhibitory to $M$. ruminantium at $\mathrm{pH} 5$ than at $\mathrm{pH} 7$ [105], the concentrate level-dependent anti-methanogenic efficacy of MCFA and PUFA is probably attributed to the lower $\mathrm{pH}$ associated with high-concentrate diets.

\section{Plant secondary metabolites}

Plants secondary metabolites (PSM), such as saponins, tannins, flavonoids, organosulphur compounds, and essential oils, have anti-microbial activities against several 
types of microorganisms [106]. Numerous PSM extracts have been recognized as potential inhibitors of rumen methanogens and $\mathrm{CH}_{4}$ production $\left.[107,108]\right)$. Some forage plants rich in tannins and saponins have also shown promise at mitigating $\mathrm{CH}_{4}$ emission from ruminants [109, 110]. However, the efficacy of PSM in suppressing $\mathrm{CH}_{4}$ production varies considerably depending on the type, sources, molecular weight, doses, as well as diet types.

\section{A) Tannins}

Tannins decrease $\mathrm{CH}_{4}$ production by directly inhibiting methanogens and indirectly decreasing $\mathrm{H}_{2}$ production as a result of decreased fiber digestion and protozoal population in the rumen [48]. The inhibitory activity of tannins extracted from Lotus pedunculatus was demonstrated on pure cultures of methanogens [111]. Puchala et al. [109] also showed inhibition of methanogen populations by tannins in the rumen of goats fed diets containing tannins. Studies on structure-activity relationships have shown that types and molecular weights of tannins are important in determining their potency in lowering $\mathrm{CH}_{4}$ production and abundance and diversity of rumen methanogens, with high molecular weight condensed tannins (CT) being more potent $[112,113]$. Such structure-activity relationships have been demonstrated using members of Methanobacteriales including Methanobrevibacter [114]. However, members of Methanomicrobiales exhibit no differential response to $\mathrm{CT}$ with different molecular weights, and unclassified Thermoplasmata-associated methanogens were even stimulated with increasing molecular weights of CT [114]. One of the CT fractions also increased the relative abundance of Methanomicrobium spp. The differential responses of methanogens to different CT and variation in the $\mathrm{CT}$ used among studies may explain the inconsistent effects reported despite using similar doses of tannins.

\section{B) Flavonoids}

Flavonoids have not been extensively evaluated with respect to rumen methanogenesis [107]. Oskoueian et al. [115] reported that inclusion of flavone, myricetin, naringin, rutin, quercetin, or kaempferol decreased in-vitro $\mathrm{CH}_{4}$ production by 5 to $9 \mathrm{~mL} / \mathrm{g} \mathrm{DM}$. Their potency ranked as follows: myricetin $\geq$ kaempferol $\geq$ flavone $>$ quercetin $\geq$ naringin $>$ rutin $\geq$ catechin. Catechin decreased $\mathrm{CH}_{4}$ production both in vitro [116] and in vivo [117]. All the flavonoids, when fed at $0.2 \mathrm{~g} / \mathrm{kg} \mathrm{DM}$, noticeably decreased relative abundances of hydrogenotrophic methanogens, and citrus (Citrus aurantium) extract rich in mixed flavonoids and its pure flavonoid components, neohesperidin and naringin, appeared to result in the greatest inhibition [118]. Methanosarcina spp. were also inhibited by poncirin, neohesperidin, naringin and their mixture. Flavonoids directly inhibit methanogens $[115,118]$ and also likely acts as $\mathrm{H}_{2}$ sinks via cleavage of ring structures (e.g., catechin) and reductive dihydroxylation [116].

\section{C) Saponins}

The effects of saponins on rumen fermentation, rumen microbial populations, and ruminant productivity have been examined extensively and reviewed previously [107, 108, 119]. Quillaja saponin at $1.2 \mathrm{~g} / \mathrm{L}$, but not at $0.6 \mathrm{~g} / \mathrm{L}$ [120], lowered $\mathrm{CH}_{4}$ production in vitro and the abundance of methanogens (by $0.2-0.3 \mathrm{log}$ ) and altered their composition. Ivy fruit saponin decreased $\mathrm{CH}_{4}$ production by $40 \%$, modified the structure of the methanogen community, and decreased its diversity [121]. Saponins from Saponaria officinalis decreased $\mathrm{CH}_{4}$ and abundance of both methanogens and protozoa in vitro [122]. However, in other in vitro studies, Quillaja saponins at $0.6 \mathrm{~g} / \mathrm{L}$ did not lower $\mathrm{CH}_{4}$ production or methanogen abundance [88, 123], and Yucca and Quillaja saponins at 0.6 to $1.2 \mathrm{~g} / \mathrm{L}$ even increased archaeal abundance (by $0.3-$ $0.4 \mathrm{log})$, despite a decrease in protozoal abundance by Quillaja saponin [124]. Tea saponins (30 g/day) also did not lower $\mathrm{CH}_{4}$ emission from steers or abundance of total methanogens but increased the abundance of RCC methanogens and protozoa [125]. Thus, the effects of saponins on methanogenesis and methanogen abundance are highly variable among studies.

Saponins probably have little direct effect on methanogens but are known to inhibit rumen protozoa, lowering $\mathrm{H}_{2}$ production and decreasing the abundance of PAM [126]. It has been estimated that PAM produce 9-25\% [127] or more (37\%) of total $\mathrm{CH}_{4}$ production [21] in sheep. The difference in PAM and their proportion of total methanogens, diet composition, and dose and chemical nature of saponins can be attributable to the discrepancies among studies.

\section{D) Essential oils}

The effects, mostly beneficial, of essential oils (EO) on rumen fermentation, microbial populations, and ruminant productivity have frequently been reviewed [108, 128-130]. Several EO compounds, either in pure form or in mixtures, are anti-methanogenic [123, 131-133]. The effects of $\mathrm{EO}$ on $\mathrm{CH}_{4}$ production and methanogens are variable depending on dose, types, and diet. Patra and $\mathrm{Yu}$ [7] compared five EO (clove, eucalyptus, peppermint, origanum, and garlic oil) that have different chemical structures in vitro at three different doses $(0.25,0.50$ and $1.0 \mathrm{~g} / \mathrm{L})$ for their effect on $\mathrm{CH}_{4}$ production and archaeal abundance and diversity. Overall, all these EO suppressed $\mathrm{CH}_{4}$ 
production and abundance of archaea and protozoa in a dose-dependent manner, but they differed in potency. Thyme oil or cinnamon oil fed to Holstein steers at $0.5 \mathrm{~g} /$ day decreased the relative abundance of total protozoa and methanogens [134]. However, feeding beef cattle a blend of $\mathrm{EO}$ (CRINA ${ }^{\circ}$ ) did not affect $\mathrm{CH}_{4}$ production, methanogen abundance or its diversity [135]. Overall, methanogens may be directly inhibited or indirectly inhibited by EOs via inhibition of protozoa and $\mathrm{H}_{2}$ -producing bacteria in the rumen [130, 131].

\section{Alternative hydrogen sinks}

Compounds with a redox potential higher than $\mathrm{CO}_{2}$ can thermodynamically outcompete $\mathrm{CO}_{2}$ for reducing equivalents produced during rumen fermentation. These compounds, thus, can be used as alternative $\mathrm{e}^{-}$acceptors to redirect $\mathrm{e}^{-}$flux away from methanogenesis. The commonly evaluated alternative $\mathrm{e}^{-}$acceptors are discussed below.

\section{A) Nitrate and sulfate}

Nitrate $\left(\mathrm{NO}_{3}^{1-}\right)$ decreased $\mathrm{CH}_{4}$ production both in vitro $[120,136,137]$ and in vivo [138-141]. Mechanistically, nitrate decreases $\mathrm{CH}_{4}$ production by outcompeting $\mathrm{CO}_{2}$ as an $\mathrm{e}^{-}$acceptor, and its reduction intermediates, nitrite $\left(\mathrm{NO}_{2}^{1-}\right)$ and nitrous oxide $\left(\mathrm{N}_{2} \mathrm{O}\right)$, also directly inhibit methanogens as well as some $\mathrm{H}_{2}$ producers $[8,120$, 142, 143]. Sulfate also lowers $\mathrm{CH}_{4}$ production, but much less effectively than nitrate. Archaeal abundance declined in goats receiving nitrate [144]. While nitrate is not toxic to methanogens, it is toxic to protozoa, fungi and to a lesser extent to select bacterial species, suggesting a more general toxicity of nitrate [143]. Nitrate can replace a portion of the dietary nitrogen as it is reduced to ammonia. However, dietary nitrate supplementation may increase the risk of nitrite poisoning (methemoglobinemia), especially when forage contains a high level of nitrate [136]. High concentrations of sulfate in diets (i.e., 0.3 to $0.4 \%$ sulfur as sulfate) can reduce feed intake, animal performance, and increase the risk of sulfur-associated polioencephalomalacia [145].

\section{B) Nitrocompounds}

A few organic nitrocompounds have been evaluated for their efficacy to decrease methanogens and $\mathrm{CH}_{4}$ production as recently reviewed by Latham et al. [146]. These compounds can serve as $\mathrm{e}^{-}$acceptors by some bacteria competing with methanogens for reducing equivalents. This is demonstrated by nitroethane that can be used as a terminal $\mathrm{e}^{-}$acceptor by Dentitrobacterium detoxificans, thereby indirectly decreasing $\mathrm{CH}_{4}$ production [146, 147]. Nitrocompounds may also inhibit methanogenesis by directly inhibiting the activity of formate dehydrogenase/formate hydrogen lyase and hydrogenase, all of which are involved in the early step(s) of the hydrogenotrophic methanogenesis pathway [148], or inhibiting $\mathrm{e}^{-}$transfer between ferredoxin and hydrogenase [146]. However, these premises have not been confirmed biochemically.

Nitrocompounds generally are quite effective in lowering $\mathrm{CH}_{4}$ production, with 3-nitro-propionate, 2-nitropropanol, 2-nitroethanol and nitroethane being able to decrease $\mathrm{CH}_{4}$ production by 57 to $98 \%$ in vitro [148]. Using sheep, Anderson et al. [147] showed that nitroethane decreased $\mathrm{CH}_{4}$ production by up to $45 \%$ and $69 \%$, respectively, when orally administrated at 24 and $72 \mathrm{mg} / \mathrm{kg}$ body weight daily for 5 days. Although less effective than nitroethane, 2nitropropanol also significantly lowered $\mathrm{CH}_{4}$ production (by 37\%) in steers. However, the effect of both nitroethane and 2-nitropropanol diminished at day 5 of administration, presumably due to microbial adaptation. In another study, daily oral administration of nitroethane up to $160 \mathrm{mg} / \mathrm{kg}$ BW failed to lower $\mathrm{CH}_{4}$ emissions in steers, and microbial transformation and adaptation were thought to be responsible for the lack of persistent efficacy [149]. Nitroethane or 2-nitropropanol generally have no effect on rumen fermentation, but due to rapid adaptation by rumen microbes, they are probably of little practical utility in methane mitigation.

\section{C) Propionate and butyrate enhancers}

Malate, acrylate, oxaloacetate, and fumarate are intermediates of carbohydrate fermentation. They can be converted to propionate or used in anabolism for the synthesis of amino acids or other molecules. They can accept reducing equivalents and thus stoichiometrically lower $\mathrm{H}_{2}$ available for $\mathrm{CH}_{4}$ production. When added at a concentration of $3.5 \mathrm{~g} / \mathrm{L}$, fumarate decreased $\mathrm{CH}_{4}$ production by $38 \%$ in continuous fermenters with forages as a substrate [150]. Types of forages and their combinations appeared to affect the anti-methanogenic efficacy of fumarate, ranging from 6 to 27\% inhibition at $10 \mathrm{mmol} / \mathrm{L}$ [151]. Acrylate also depresses $\mathrm{CH}_{4}$ production in the rumen, but to a lesser extent than an equimolar level of fumarate. Malate was found to decrease $\mathrm{CH}_{4}$ production by beef cattle in a dose-dependent manner, with a $16 \%$ decrease being noted when fed at $7.5 \%$ of DM intake, which corresponds to a $9 \%$ reduction per unit of DM intake [152]. Different studies reported different anti-methanogenic potencies of this type of $\mathrm{e}^{-}$acceptors. Fumarate fed to goats at $10 \mathrm{~g} /$ day/goat was found to decrease the abundance of methanogens and $\mathrm{CH}_{4}$ production only by $11.9 \%$ while increasing concentrations of total VFA, acetate and propionate [153]. However, $\mathrm{CH}_{4}$ emissions were not lowered by tartrate, 
malate, fumarate, or citrate at up to $15 \mathrm{mmol} / \mathrm{L}$ in vitro [154], or by oxaloacetate at up to $18 \mathrm{mmol} / \mathrm{L}$ in vitro [155]. Fumarate fed at up to $29 \mathrm{~g} / \mathrm{kg} \mathrm{DM}$ did not decrease $\mathrm{CH}_{4}$ emission from beef cattle [156]. Some of the intermediates of pyruvate conversion to butyrate can act as $\mathrm{e}^{-}$acceptors, which could also decrease $\mathrm{CH}_{4}$ production. Ungerfeld et al. [155] evaluated acetoacetate, $\beta$ hydroxybutyrate, and crotonic acid at up to $18 \mathrm{mmol} / \mathrm{L}$ in vitro. $\beta$-Hydroxybutyrate did not lower $\mathrm{CH}_{4}$ production, while the other two intermediates only decreased $\mathrm{CH}_{4}$ production by $\leq 18 \%$. The inconsistent efficacies reported in the literature can be attributed to many factors, including variation in diet used and type and dose tested. Besides, these intermediates can be converted to acetate, rather than propionate or butyrate, thereby stoichiometrically increasing $\mathrm{CH}_{4}$ production [157]. Nonetheless, it is probably cost-prohibitive to use these organic acids to lower $\mathrm{CH}_{4}$ emissions on farms.

\section{D) Unsaturated organic acids}

Unsaturated fatty acids can act as hydrogen sinks during their biohydrogenation and thereby lower $\mathrm{CH}_{4}$ production. Propynoic acid (an unsaturated analog of propionic acid), 3-butenoic acid and 2-butynoic acid (both unsaturated analogs of butyric acid), and ethyl 2butynoate each at 6 to $18 \mathrm{mmol} / \mathrm{L}$ have been evaluated as alternative $\mathrm{e}^{-}$sinks to lower methanogenesis in vitro [155]. Only propynoic acid and ethyl 2-butynoate markedly lowered $\mathrm{CH}_{4}$ production, by 65 to $76 \%$ and 24 to $79 \%$, respectively [155]. In another study, propynoic acid lowered $\mathrm{CH}_{4}$ production by $67 \%$ and $78 \%$ at 6 and $12 \mathrm{mmol} / \mathrm{L}$, respectively and decreased methanogen abundance [120]. Propynoic acid and ethyl 2-butynoate are directly toxic to methanogens, and species of methanogens vary in their sensitivity to these two inhibitors, with Mbb. Ruminantium being most sensitive, Ms. mazei least sensitive, and Mm. mobile intermediate [52]. The S-layer in Ms. Mazei and Mm. mobile (absent in $M b b$. ruminantium) may confer some resistance to propynoic acid and ethyl 2-butynoate. Selective resistance to these compounds among different species can favor the proliferation of resistant species over time, diminishing any initial decreases in enteric $\mathrm{CH}_{4}$ production, which makes it ineffective to use these inhibitors in vivo.

\section{Inhibitors to hydrogen-producing bacteria}

\section{A) Ionophores}

Ionophores, such as monensin and lasalocid, are commonly used to improve rumen microbial metabolism. Being highly lipophilic ion carriers, they pass through the cell wall of Gram-positive bacteria and penetrate into the cell membrane. Therein, they serve as $\mathrm{H}^{+} / \mathrm{Na}^{+}$ and $\mathrm{H}^{+} / \mathrm{K}^{+}$antiporters, dissipating ion gradients that are needed for ATP synthesis, nutrient transport, and other essential cellular activities and ultimately resulting in delayed cell division and even cell death [158]. Ionophores preferentially inhibit Gram-positive bacteria, including members of class Clostridia, including Ruminococcus species that produce acetate and $\mathrm{H}_{2}$ [159]. Ionophores can also inhibit some Gram-negative rumen bacteria $[160,161]$, including bacteria that produce formate and $\mathrm{H}_{2}$ [159]. Therefore, ionophores may lower $\mathrm{CH}_{4}$ emission by decreasing $\mathrm{H}_{2}$ production. For examples, monensin fed at $24-35 \mathrm{mg} / \mathrm{kg}$ diet lowered $\mathrm{CH}_{4}$ production by up to $10 \%$ (g/kg DM intake) [162-165], though no $\mathrm{CH}_{4}$ suppression was observed at $10-15 \mathrm{ppm}$. In a recent in vivo study, however, monensin at $60 \mathrm{mg} /$ day/cow did not lower $\mathrm{CH}_{4}$ production by tropical cattle, though it decreased $\mathrm{CH}_{4}$ production by about $30 \%$ when fed at $250 \mathrm{mg} /$ day/cow [135]. As repeatedly noted, at such high supplementation level, DM intake was lowered, which explains most of the observed decrease in $\mathrm{CH}_{4}$ emission. Ionophores are not known to directly inhibit methanogens, but they can change the population dynamics of methanogen species. For example, monensin decreased the population of Methanomicrobium spp. while increasing that of Methanobrevibacter spp. [135]. Total methanogens were also decreased in cattle fed monensin [134]. These can be explained by reduced availability of $\mathrm{H}_{2}$ and differences in affinity for $\mathrm{H}_{2}$ and growth kinetics among methanogen species.

\section{B) Bacteriocins}

Bacteriocins are proteins or peptides produced by bacteria and inhibit select microbial species in the rumen and other habitats. There are only a few studies investigating the effect of bacteriocins on $\mathrm{CH}_{4}$ emission. Bovicin $\mathrm{HC}$, a bacteriocin produced by Streptococcus spp. from the rumen, was reported to suppress $\mathrm{CH}_{4}$ by $50 \%$ in vitro [166]. Nisin, a bacteriocin produced by Lactobacillus lactis subsp. lactis, has also been shown to decrease $\mathrm{CH}_{4}$ production in vitro by up to $40 \%$ depending upon its concentration [167]. Similar to monensin, bacteriocins probably modulate rumen fermentation leading towards increased propionate, thereby decreasing $\mathrm{CH}_{4}$ production. Bacteriocins may hold some potential in mitigating enteric $\mathrm{CH}_{4}$ emission, but further research is needed to confirm their efficacy in vivo and to determine their cost.

\section{Use of combination of anti-methanogenic inhibitors}

Most of the aforementioned anti-methanogenic inhibitors have repeatedly been evaluated, primarily individually, both in vitro and in vivo, to decrease enteric $\mathrm{CH}_{4}$ production. With a few exception (e.g., nitrate and 3NOP), most 
of them often decrease feed intake, feed digestion, and rumen fermentation when added at high enough doses to achieve effective $\mathrm{CH}_{4}$ inhibition [120]. Some of these inhibitors (e.g., halogenated aliphatic hydrocarbons) are also toxic to animals [168]. Adverse effects or toxicity can be avoided by using combinations of inhibitors with complementary modes of actions at low doses to inhibit not only methanogens but also other rumen microbes (e.g., protozoa and $\mathrm{H}_{2}$-producing bacteria) that contribute to $\mathrm{CH}_{4}$ production in an additive or synergistic manner [120]. Binary combinations of nitrate and Quillaja saponin inhibited $\mathrm{CH}_{4}$ production additively in vitro (by $32 \%$ at $5 \mathrm{mmol}$ nitrate/L and $0.6 \mathrm{~g} / \mathrm{L}$ saponins, and by $58 \%$ at $10 \mathrm{mmol}$ nitrate/L and $1.2 \mathrm{~g} / \mathrm{L}$ saponins) and decreased the abundances of methanogens without affecting feed digestion or fermentation [120]. This binary combination probably additively lowered $\mathrm{CH}_{4}$ production by channeling $\mathrm{H}_{2}$ away from methanogenesis to nitrate reduction, directly inhibiting methanogens by nitrite (the intermediate of nitrate reduction), and inhibiting protozoa and their PAM [120]. Combinations of garlic oil and nitrate, garlic oil and nitrate and saponin, and saponin and nitrate and sulfate all considerably decreased $\mathrm{CH}_{4}$ production and abundance of methanogens and altered the species composition of methanogens in vitro without other adverse effects $[8,88,169]$. Monensin in combination with ethanol extract of hops (Humuluslupulus, containing $\beta$ - and $\alpha$ acids) or Yucca saponin decreased $\mathrm{CH}_{4}$ in an additive manner in vitro, but unfortunately, microbial protein synthesis was also decreased [170]. Use of a combination of different anti-methanogenic inhibitors is a relatively new approach, and only a few in vivo studies have been reported. Combinations of nitrate and sulfate additively lowered $\mathrm{CH}_{4}$ production in sheep without decreasing feed digestibility or fermentation $[8,120,142,143]$. These were also observed in dairy cows when fed combinations of nitrate and linseed oil [171]. Because $\mathrm{CH}_{4}$ production in the rumen involves methanogens and several groups of other microbes, combinations of inhibitors with complementary modes of actions represent a paradigm shift in achieving effective and practical $\mathrm{CH}_{4}$ mitigation from ruminants. Future research can help optimize combinations and doses to achieve sustainable and practical $\mathrm{CH}_{4}$ mitigation from ruminants.

\section{Concluding remarks and future perspectives}

Previous research has helped reach a sound understanding and appreciation of the diversity of rumen methanogens in general. However, variations among individual animals are ubiquitous, and the underpinning of such variation is poorly understood. The relationship between animal performance and diversity/population dynamics also remains to be determined and elucidated. Additionally, methanogens associated with protozoa and fungi continue to be elusive, so does their symbiotic relationship with these two groups of eukaryotes and phages. Moreover, it is unknown to what extent phages, both bacterial and archaeal, affect the population dynamics of rumen bacteria and methanogens and thus $\mathrm{CH}_{4}$ emission. Because these methanogens and their symbiotic relationship affect fermentation and $\mathrm{CH}_{4}$ emission from ruminants, more future research is warranted.

A large number of synthetic and natural compounds have been tested, but most of them exhibited inconsistent efficacy. Variations in rumen microbiome, fermentation kinetics, response and adaptation to anti-methanogenic inhibitors, and diet are probably among the major factors that contribute to the inconsistent efficacy. More importantly from an application perspective, the desired decrease in $\mathrm{CH}_{4}$ production often is accompanied by significant reduction in feed intake, digestion, and fermentation. Given that $\mathrm{CH}_{4}$ production in the rumen is a multifaceted process involving methanogens as well as many different $\mathrm{H}_{2}$-producing microbes, such challenges are expected. Future ecological and physiological research on methanogens and other microbes involved in $\mathrm{CH}_{4}$ production can help predict the efficacy of anti-methanogenic compounds. Combinations of anti-methanogenic compounds with complementary modes of actions are a promising approach to achieve effective $\mathrm{CH}_{4}$ mitigation without adverse effects on feed intake and rumen fermentation. Mechanistic research on most anti-methanogenic inhibitors lags behind empirical studies. Future mechanistic research will help formulate new combinations and optimize their composition and doses to achieve persistent and effective $\mathrm{CH}_{4}$ emission. A cost-benefit assessment of the mitigation options and carbon footprint analysis of the livestock products using an integrated life cycle assessment needs to be done before any $\mathrm{CH}_{4}$ mitigation effort can be put into practice. There are also several other challenges in using some of the anti-methanogenic compounds in ruminant production. For some of the antimethanogenic substances, especially synthetic compounds, it may be difficult to obtain regulatory approval for commercial applications on farms. There are also challenges for the administration of the compounds, especially to ruminants that are under extensive grazing conditions. This is especially important as the cattle grazing pasture make the largest contribution to enteric methane emissions globally.

\footnotetext{
Abbreviations

3NOP: 3-nitrooxypropanol; BCM: Bromochloromethane; BES: 2bromoethanesulfonate; BPS: 3-bromopropanesulfonate; CES: 2-

chloroethanesulfoante; $\mathrm{CH}_{4}$ : Methane; $\mathrm{CO}_{2}$ : Carbon dioxide; $\mathrm{CoA}$ : Coenzyme A; CoM: Coenzyme M; CT: Condensed tannins; $\mathrm{e}^{-}$: Electron; EO: Essential oils; $\mathrm{F}_{420}$ : Deazaflavin; FAM: Fungi-associated methanogens; FISH: Fluorescence in situ hybridization; $\mathrm{H}_{2}$ : Hydrogen gas; HMG-S-CoA: Hydroxymethylgluaryl-CoA; Mbb.: Methanobrevibacter; MCFA: Medium-chain fatty acids; Mcr: Methyl-CoM reductase; Ms.: Methanosarcina; NGS: Next-generation sequencing; PAM: Protozoa-associated methanogens; PSM: Plant secondary metabolites; RCC: Rumen cluster C; RDP: Ribosomal database project; Rusitec: Rumen
} 
simulation technique; T-RFLP: Terminal restriction fragment length polymorphism; VFA: Volatile fatty acids

\section{Acknowledgements}

Not applicable.

\section{Funding}

Research in Dr. Yu's lab is supported by funding (award number: 201267015-19437) from the Agriculture and Food Research Initiative (AFRI) of National Institute of Food and Agriculture (NIFA), US Department of Agriculture.

\section{Availability of data and material}

The datasets analyzed during the current study are available from the corresponding author on reasonable request.

\section{Authors' contributions}

AP, TP, and MK searched the primary literature and databases, compiled available data. ZY organized the content and structure of the manuscript. All the authors wrote and edited the manuscript. All authors have read and approved the final manuscript and take full responsibility for the final content.

\section{Competing interests}

The authors declare no conflicts of interest.

\section{Consent for publication}

This review article does not contain any individual personal data.

\section{Ethics approval and consent to participate}

This review article does not involve any human subject, or human data.

\section{Author details}

'Department of Animal Sciences, The Ohio State University, 2029 Fyffe Road, Columbus, OH 43210, USA. ²Department of Animal Nutrition, West Bengal University of Animal and Fishery Sciences, 37 K. B. Sarani, Belgachia, Kolkata 700037, India. ${ }^{3}$ Animal Nutrition and Physiology Team, National Institute of Animal Science, Rural Development Administration, Wanju 55365, Republic of Korea.

Received: 2 August 2016 Accepted: 13 January 2017

Published online: 26 January 2017

\section{References}

1. Rother M, Krzycki JA. Selenocysteine, pyrrolysine, and the unique energy metabolism of methanogenic archaea. Archaea. 2010;2010:453642.

2. Vogels GD, Hoppe WF, Stumm CK. Association of methanogenic bacteria with rumen ciliates. Appl Environ Microbiol. 1980:40:608-12.

3. Hegarty R, Klieve A. Opportunities for biological control of ruminal methanogenesis. Crop Pasture Sci. 1999:50:1315-20.

4. Brul S, Stumm CK. Symbionts and organelles in ancrobic protozoa and fungi. Trends Ecol Evol. 1994:9:319-24.

5. Valle ER, Henderson G, Janssen PH, Cox F, Alexander TW, McAllister TA Considerations in the use of fluorescence in situ hybridization (FISH) and confocal laser scanning microscopy to characterize rumen methanogens and define their spatial distributions. Can J Microbiol. 2015;61:417-28.

6. Rychlik JL, May T. The effect of a methanogen, Methanobrevibacter smithii, on the growth rate, organic acid production, and specific ATP activity of three predominant ruminal cellulolytic bacteria. Curr Microbiol. 2000;40:176-80.

7. Patra AK, Yu Z. Effects of essential oils on methane production and fermentation by, and abundance and diversity of, rumen microbial populations. Appl Environ Microbiol. 2012;78:4271-80.

8. Patra A, Yu Z. Effects of garlic oil, nitrate, saponin and their combinations supplemented to different substrates on in vitro fermentation, ruminal methanogenesis, and abundance and diversity of microbial populations. J Appl Microbiol. 2015;119:127-38.

9. Lopes J, de Matos L, Harper M, Giallongo F, Oh J, Gruen D, et al. Effect of 3-nitrooxipropanol on methane and hydrogen emissions, methane isotopic signature, and ruminal fermentation in dairy cows. J Dairy Sci. 2016:99:5335-44.

10. Knapp JR, Laur GL, Vadas PA, Weiss WP, Tricarico JM. Invited review: Enteric methane in dairy cattle production: Quantifying the opportunities and impact of reducing emissions. J Dairy Sci. 2014;97:3231-61.
11. Johnson KA, Johnson DE. Methane emissions from cattle. J Anim Sci. 1995; 73:2483-92.

12. Ziemer CJ, Sharp R, Stern MD, Cotta MA, Whitehead TR, Stahl DA. Comparison of microbial populations in model and natural rumens using $16 \mathrm{~S}$ ribosomal RNA-targeted probes. Environ Microbiol. 2000;2:632-43.

13. Janssen PH, Kirs M. Structure of the archaeal community of the rumen. Appl Environ Microbiol. 2008;74:3619-25.

14. Lee J-H, Kumar S, Lee G-H, Chang D-H, Rhee M-S, Yoon M-H, et al. Methanobrevibacter boviskoreani sp. nov., isolated from the rumen of Korean native cattle. Intl J Syst Evol Microbiol. 2013;63:4196-201.

15. Wright A-DG, Auckland $\mathrm{CH}$, Lynn DH. Molecular diversity of methanogens in feedlot cattle from Ontario and Prince Edward Island, Canada. Appl Environ Microbiol. 2007;73:4206-10.

16. Wright AD, Ma X, Obispo NE. Methanobrevibacter phylotypes are the dominant methanogens in sheep from Venezuela. Microb Ecol. 2008;56:390-4.

17. Belanche A, de la Fuente G, Newbold CJ. Study of methanogen communities associated with different rumen protozoal populations. FEMS Microbiol Ecol. 2014;90(3):663-77.

18. Leng R. Interactions between microbial consortia in biofilms: A paradigm shift in rumen microbial ecology and enteric methane mitigation. Anim Prod Sci. 2014:54:519-43.

19. Müller M. Review article: The hydrogenosome. Microbiol. 1993;139:2879-89.

20. Wrede C, Dreier A, Kokoschka S, Hoppert M. Archaea in symbioses. Archaea. 2012;2012:596846

21. Finlay BJ, Esteban G, Clarke KJ, Williams AG, Embley TM, Hirt RP. Some rumen ciliates have endosymbiotic methanogens. FEMS Microbiol Lett. 1994;117:157-61.

22. Krumholz LR, Forsberg CW, Veira DM. Association of methanogenic bacteria with rumen protozoa. Can J Microbiol. 1983;29:676-80.

23. Stumm C, Gijzen H, Vogels G. Association of methanogenic bacteria with ovine rumen ciliates. Br J Nutr. 1982:47:95-9.

24. Lloyd D, Williams AG, Amann R, Hayes AJ, Durrant L, Ralphs JR. Intracellular prokaryotes in rumen ciliate protozoa: Detection by confocal laser scanning microscopy after in situ hybridization with fluorescent 16S rRNA probes. Eur J Protistol. 1996:32:523-31.

25. Muller M. Energy metabolism of protozoa without mitochondria. Ann Rev Microbiol. 1988:42:465-88.

26. Williams A, Coleman G. The rumen protozoa. Springer Series in Contemporary Bioscience. New York: Springer; 1992.

27. Tokura M, Tajima K, Ushida K. Isolation of Methanobrevibacter sp. as a ciliateassociated ruminal methanogen. J Gen Appl Microbiol. 1999:45:43-7.

28. Chagan I, Tokura M, Jouany JP, Ushida K. Detection of methanogenic archaea associated with rumen ciliate protozoa. J Gen Appl Microbiol. 1999;45:305-8.

29. Tokura M, Chagan I, Ushida K, Kojima Y. Phylogenetic study of methanogens associated with rumen ciliates. Curr Microbiol. 1999;39:123-8.

30. Irbis C, Ushida K. Detection of methanogens and Proteobacteria from a single cell of rumen ciliate protozoa. J Gen Appl Microbiol. 2004;50:203-12.

31. Regensbogenova M, McEwan N, Javorsky P, Kisidayova S, Michalowski T, Newbold C, et al. A re-appraisal of the diversity of the methanogens associated with the rumen ciliates. FEMS Microbiol Lett. 2004:238:307-13.

32. Ohene-Adjei S, Teather RM, Ivan M, Forster RJ. Postinoculation protozoan establishment and association patterns of methanogenic archaea in the ovine rumen. Appl Environ Microbiol. 2007;73:4609-18.

33. Tymensen LD, McAllister TA. Community structure analysis of methanogens associated with rumen protozoa reveals bias in universal archaeal primers. Appl Environ Microbiol. 2012;78:4051-6.

34. Morgavi DP, Jouany JP, Martin C, Ranilla MJ. Archaeal community structure diversity in the rumen of faunated and defaunated sheep. Intl Congress Series. 2006;1293:127-30.

35. Ozutsumi Y, Tajima K, Takenaka A, Itabashi $\mathrm{H}$. The mcrA gene and 165 rRNA gene in the phylogenetic analysis of methanogens in the rumen of faunated and unfaunated cattle. Anim Sci J. 2012;83:727-34.

36. Xia $Y$, Kong $Y H$, Seviour R, Forster RJ, Kisidayova S, McAllister TA. Fluorescence in situ hybridization probing of protozoal entodinium spp. and their methanogenic colonizers in the rumen of cattle fed alfalfa hay or triticale straw. J Appl Microbiol. 2014;116:14-22.

37. Takenaka A, Itabashi $\mathrm{H}$. Changes in the population of some functional groups of rumen bacteria including methanogenic bacteria by changing the rumen ciliates in calves. J Gen Appl Microbiol. 1995:41:377-87.

38. de la Fuente $G$, Fondevila M, Belanche A, Morgavi D. In vitro predation of pure bacterial species by rumen protozoa from monofaunated sheep, determined by qPCR. Options Mediterraneennes. 2011;99:91-6. 
39. Marvin-Sikkema FD, Lahpor GA, Kraak MN, Gottschal JC, Prins RA. Characterization of an anaerobic fungus from ilama faeces. Microbiol. 1992;138:2235-41.

40. Jin W, Cheng Y-F, Mao S-Y, Zhu W-Y. Isolation of natural cultures of anaerobic fungi and indigenously associated methanogens from herbivores and their bioconversion of lignocellulosic materials to methane. Bioresour Technol. 2011;102:7925-31.

41. Jin W, Cheng YF, Mao SY, Zhu WY. Discovery of a novel rumen methanogen in the anaerobic fungal culture and its distribution in the rumen as revealed by real-time PCR. BMC Microbiol. 2014;14:104.

42. Wei $Y-Q$, Long R-J, Yang $H$, Yang $H-J$, Shen $X-H$, Shi R-F, et al. Fiber degradation potential of natural co-cultures of Neocallimastix frontalis and Methanobrevibacter ruminantium isolated from yaks (Bos grunniens) grazing on the Qinghai Tibetan Plateau. Anaerobe. 2016;39:158-64.

43. Orpin CG. Nutrition and biochemistry of anaerobic Chytridiomycetes. Biosystems. 1988;21:365-70.

44. Morgavi D, Forano E, Martin C, Newbold C. Microbial ecosystem and methanogenesis in ruminants. Animal. 2010;4:1024-36.

45. Wolin MJ, Miller TL, Stewart CS. Microbe-microbe interactions. In: Hobson PN, Stewart CS, editors. The rumen microbial ecosystem. 2nd ed. New York: Blackie Academic and Professional; 1997. p. 467-91.

46. Latham M, Wolin M. Fermentation of cellulose by ruminococcus flavefaciens in the presence and absence of Methanobacterium ruminantium. Appl Environ Microbiol. 1977;34:297-301.

47. Scheifinger $\mathrm{C}$, Linehan $\mathrm{B}$, Wolin $\mathrm{M} . \mathrm{H}_{2}$ production by Selenomonas ruminantium in the absence and presence of methanogenic bacteria. Appl Microbiol. 1975;29:480-3.

48. Patra AK, Min B-R, Saxena J. Dietary tannins on microbial ecology of the gastrointestinal tract in ruminants. In: Patra AK, editor. Diet Phytochem Microbes. Dordrecht: Springer Netherlands; 2012. p. 237-62

49. Hristov A, Oh J, Firkins J, Dijkstra J, Kebreab E, Waghorn G, et al. Special topics - mitigation of methane and nitrous oxide emissions from animal operations: I. A review of enteric methane mitigation options. J Anim Sci. 2013;91:5045-69.

50. Liu Y, Whitman WB. Metabolic, phylogenetic, and ecological diversity of the methanogenic archaea. Ann N Y Acad Sci. 2008;1125:171-89.

51. Nollet L, Demeyer D, Verstraete W. Effect of 2-bromoethanesulfonic acid and Peptostreptococcus productus ATCC 35244 addition on stimulation of reductive acetogenesis in the ruminal ecosystem by selective inhibition of methanogenesis. Appl Environ Microbiol. 1997;63:194-200.

52. Ungerfeld E, Rust S, Boone D, Liu Y. Effects of several inhibitors on pure cultures of ruminal methanogens. J Appl Microbiol. 2004;97:520-6.

53. Smith M. Reversal of 2-bromoethanesulfonate inhibition of methanogenesis in Methanosarcina sp. J Bacteriol. 1983;156:516-23.

54. Balch WE, Wolfe RS. Transport of coenzyme M (2-mercaptoethanesulfonic acid) in Methanobacterium ruminantium. J Bacteriol. 1979;137:264-73.

55. Stewart C, Flint H, Bryant M. The rumen bacteria. In: Hobson PN, Stewart CS editors. The rumen microbial ecosystem. 2nd ed. New York: Chapman and Hall; 1997. p. 10-72.

56. Van Nevel C, Demeyer D. Control of rumen methanogenesis. Environ Monit Assess. 1996:42:73-97.

57. Karnati SK, Sylvester JT, Ribeiro CV, Gilligan LE, Firkins JL. Investigating unsaturated fat, monensin, or bromoethanesulfonate in continuous cultures retaining ruminal protozoa. I. Fermentation, biohydrogenation, and microbial protein synthesis. J Dairy Sci. 2009;92:3849-60.

58. Wood J, Kennedy FS, Wolfe R. Reaction of multihalogenated hydrocarbons with free and bound reduced vitamin $B_{12}$. Biochem. 1968;7:1707-13.

59. Yu Z, Smith GB. Inhibition of methanogenesis by C1-and C2-polychlorinated aliphatic hydrocarbons. Environ Toxicol Chem. 2000;19:2212-7.

60. Knight T, Ronimus R, Dey D, Tootill C, Naylor G, Evans P, et al. Chloroform decreases rumen methanogenesis and methanogen populations without altering rumen function in cattle. Anim Feed Sci Technol. 2011;166:101-12.

61. Goel G, Makkar HP, Becker K. Inhibition of methanogens by bromochloromethane: Effects on microbial communities and rumen fermentation using batch and continuous fermentations. Br J Nutr. 2009; 101:1484-92.

62. Tomkins N, Colegate S, Hunter R. A bromochloromethane formulation reduces enteric methanogenesis in cattle fed grain-based diets. Anim Prod Sci. 2009;49:1053-8.

63. Abecia L, Toral P, Martín-García A, Martínez G, Tomkins N, Molina-Alcaide E, et al. Effect of bromochloromethane on methane emission, rumen fermentation pattern, milk yield, and fatty acid profile in lactating dairy goats. J Dairy Sci. 2012;95:2027-36.

64. Scholten JC, Conrad R, Stams AJ. Effect of 2-bromo-ethane sulfonate, molybdate and chloroform on acetate consumption by methanogenic and sulfate-reducing populations in freshwater sediment. FEMS Microbiol Ecol. 2000;32:35-42.

65. Gribble GW. The natural production of organobromine compounds. Environ Sci Pollut Res. 2000;7:37-49.

66. Machado L, Magnusson M, Paul NA, de Nys R, Tomkins N. Effects of marine and freshwater macroalgae on in vitro total gas and methane production. PLoS One. 2014;9:e85289.

67. Duin EC, Wagner T, Shima S, Prakash D, Cronin B, Yáñez-Ruiz DR, et al. Mode of action uncovered for the specific reduction of methane emissions from ruminants by the small molecule 3-nitrooxypropanol. Proc Natl Acad Sci USA. 2016:113(22): p. 6172-77.

68. Haisan J, Sun Y, Guan L, Beauchemin K, Iwaasa A, Duval S, et al. The effects of feeding 3-nitrooxypropanol on methane emissions and productivity of Holstein cows in mid lactation. J Dairy Sci. 2014;97:3110-9.

69. Romero-Perez A, Okine E, McGinn S, Guan L, Oba M, Duval S, et al. Sustained reduction in methane production from long-term addition of 3-nitrooxypropanol to a beef cattle diet. J Anim Sci. 2015:93:1780-91.

70. Haisan J, Sun Y, Guan L, Beauchemin KA, Iwaasa A, Duval S, et al. The effects of feeding 3-nitrooxypropanol at two doses on milk production, rumen fermentation, plasma metabolites, nutrient digestibility, and methane emissions in lactating Holstein cows. Anim Prod Sci. 2017;57:282-9.

71. Martínez-Fernández G, Abecia L, Arco A, Cantalapiedra-Hijar G, Martín-García A, Molina-Alcaide E, et al. Effects of ethyl-3-nitrooxy propionate and 3nitrooxypropanol on ruminal fermentation, microbial abundance, and methane emissions in sheep. J Dairy Sci. 2014;97:3790-9.

72. Reynolds CK, Humphries DJ, Kirton P, Kindermann M, Duval S, Steinberg W. Effects of 3-nitrooxypropanol on methane emission, digestion, and energy and nitrogen balance of lactating dairy cows. J Dairy Sci. 2014;97:3777-89.

73. Nagar-Anthal KR, Worrell VE, Teal R, Nagle DP. The pterin lumazine inhibits growth of methanogens and methane formation. Arch Microbiol. 1996;166:136-40.

74. Dumitru R, Palencia H, Schroeder SD, DeMontigny BA, Takacs JM, Rasche $\mathrm{ME}$, et al. Targeting methanopterin biosynthesis to inhibit methanogenesis. Appl Environ Microbiol. 2003;69:7236-41.

75. De Rosa M, Gambacorta A, Gliozzi A. Structure, biosynthesis, and physicochemical properties of archaebacterial lipids. Microbiol Rev. 1986;50:70-80.

76. Smit A, Mushegian A. Biosynthesis of isoprenoids via mevalonate in archaea: The lost pathway. Genome Res. 2000;10:1468-84.

77. Sharma A, Chaudhary PP, Sirohi S, Saxena J. Structure modeling and inhibitor prediction of NADP oxidoreductase enzyme from Methanobrevibacter smithii. Bioinformation. 2011;6:15-9.

78. Wolin M, Miller T, editors. Control of rumen methanogenesis by inhibiting the growth and activity of methanogens with hydroxymethylglutaryl-SCoA inhibitors. Int Congress Series. 2006;1293:131-7.

79. Soliva CR, Amelchanka SL, Duval SM, Kreuzer M. Ruminal methane inhibition potential of various pure compounds in comparison with garlic oil as determined with a rumen simulation technique (RUSITEC) Br J Nutr. 2011;106:114-22.

80. Endo A. The discovery and development of HMG-COA reductase inhibitors. J Lipid Res. 1992;33:1569-82.

81. Alarcon J, Aguila S, Arancibia-Avila P, Fuentes O, Zamorano-Ponce E, Hernández M. Production and purification of statins from Pleurotus ostreatus (basidiomycetes) strains. Zeitschrift Naturforschung C. 2003;58:62-4.

82. Faseleh Jahromi M, Liang JB, Mohamad R, Goh YM, Shokryazdan P, Ho YW. Lovastatin-enriched rice straw enhances biomass quality and suppresses ruminal methanogenesis. BioMed Res Int. 2013;2013:397934.

83. Faseleh Jahromi M, Liang JB, Ho YW, Mohamad R, Goh YM, Shokryazdan P, et al. Lovastatin in Aspergillus terreus: Fermented rice straw extracts interferes with methane production and gene expression in Methanobrevibacter smithii. BioMed Res Int. 2013;2013:604721.

84. Cosgrove G, Muetzel S, Skipp R, Mace W. Effects of endophytic and saprophytic fungi on in vitro methanogenesis. N Z J Agric Res. 2012;55:293-307.

85. Morgavi D, Martin C, Boudra H. Fungal secondary metabolites from Monascus spp. reduce rumen methane production in vitro and in vivo. J Anim Sci. 2013;91:848-60.

86. Gallo A, Giuberti G, Frisvad JC, Bertuzzi T, Nielsen KF. Review on mycotoxin issues in ruminants: Occurrence in forages, effects of mycotoxin ingestion 
on health status and animal performance and practical strategies to counteract their negative effects. Toxins (Basel). 2015;7:3057-111.

87. Gebhardt R, Beck H. Differential inhibitory effects of garlic-derived organosulfur compounds on cholesterol biosynthesis in primary rat hepatocyte cultures. Lipids. 1996;31:1269-76.

88. Patra AK, Yu Z. Effects of adaptation of in vitro rumen culture to garlic oil, nitrate, and saponin and their combinations on methanogenesis, fermentation, and abundances and diversity of microbial populations. Front Microbiol. 2015;6:1434.

89. Klevenhusen F, Duval S, Zeitz JO, Kreuzer M, Soliva CR. Diallyl disulphide and lovastatin: Effects on energy and protein utilisation in, as well as methane emission from, sheep. Arch Anim Nutr. 2011;65:255-66.

90. Vasta V, Luciano $\mathrm{G}$. The effects of dietary consumption of plants secondary compounds on small ruminants' products quality. Small Ruminant Res. 2011:101:150-9.

91. Wedlock D, Pedersen G, Denis M, Dey D, Janssen P, Buddle B. Development of a vaccine to mitigate greenhouse gas emissions in agriculture: Vaccination of sheep with methanogen fractions induces antibodies that block methane production in vitro. N Z Vet J. 2010;58:29-36.

92. Wright A, Kennedy P, O'Neill C, Toovey A, Popovski S, Rea S, et al. Reducing methane emissions in sheep by immunization against rumen methanogens. Vaccine. 2004;22:3976-85.

93. Williams YJ, Popovski S, Rea SM, Skillman LC, Toovey AF, Northwood KS, et al. A vaccine against rumen methanogens can alter the composition of archaeal populations. Appl Environ Microbiol. 2009;75:1860-6.

94. Wedlock D, Janssen P, Leahy S, Shu D, Buddle B. Progress in the development of vaccines against rumen methanogens. Animal. 2013;7:244-52.

95. Soliva CR, Meile L, Hindrichsen IK, Kreuzer M, Machmüller A. Myristic acid supports the immediate inhibitory effect of lauric acid on ruminal methanogens and methane release. Anaerobe. 2004;10:269-76.

96. Moate P, Williams S, Grainger C, Hannah M, Ponnampalam E, Eckard R. Influence of cold-pressed canola, brewers grains and hominy meal as dietary supplements suitable for reducing enteric methane emissions from lactating dairy cows. Anim Feed Sci Technol. 2011;166:254-64.

97. Patra AK. The effect of dietary fats on methane emissions, and its other effects on digestibility, rumen fermentation and lactation performance in cattle: A meta-analysis. Livest Sci. 2013;155:244-54.

98. Patra AK. A meta-analysis of the effect of dietary fat on enteric methane production, digestibility and rumen fermentation in sheep, and a comparison of these responses between cattle and sheep. Livest Sci. 2014;162:97-103.

99. Patra A, Yu Z. Effects of coconut and fish oils on ruminal methanogenesis, fermentation, and abundance and diversity of microbial populations in vitro J Dairy Sci. 2013;96:1782-92.

100. Grainger C, Williams R, Clarke T, Wright A-D, Eckard R. Supplementation with whole cottonseed causes long-term reduction of methane emissions from lactating dairy cows offered a forage and cereal grain diet. J Dairy Sci. 2010; 93:2612-9.

101. Jordan E, Lovett D, Monahan F, Callan J, Flynn B, O'Mara F. Effect of refined coconut oil or copra meal on methane output and on intake and performance of beef heifers. J Anim Sci. 2006;84:162-70.

102. Lillis L, Boots B, Kenny D, Petrie K, Boland T, Clipson N, et al. The effect of dietary concentrate and soya oil inclusion on microbial diversity in the rumen of cattle. J Appl Microbiol. 2011;111:1426-35.

103. Beauchemin KA, McGinn SM, Benchaar C, Holtshausen L. Crushed sunflower, flax, or canola seeds in lactating dairy cow diets: Effects on methane production, rumen fermentation, and milk production. J Dairy Sci. 2009;92:2118-27.

104. Zhou X, Meile L, Kreuzer M, Zeitz JO. The effect of saturated fatty acids on methanogenesis and cell viability of Methanobrevibacter ruminantium. Archaea. 2013;2013:106916.

105. Zhou X, Zeitz J, Meile L, Kreuzer M, Schwarm A. Influence of pH and the degree of protonation on the inhibitory effect of fatty acids in the ruminal methanogen Methanobrevibacter ruminantium strain M1. J Appl Microbiol. 2015;119:1482-93.

106. Patra AK. An overview of antimicrobial properties of different classes of phytochemicals. In: Patra AK editor. Diet Phytochemicals and Microbes: Dorrecht: Springer Netherlands; 2012. p. 1-32.

107. Patra AK, Saxena J. A new perspective on the use of plant secondary metabolites to inhibit methanogenesis in the rumen. Phytochem. 2010;71:1198-222.

108. Cieslak A, Szumacher-Strabel M, Stochmal A, Oleszek W. Plant components with specific activities against rumen methanogens. Animal. 2013;7 Suppl 2: 253-65.
109. Puchala R, Animut G, Patra A, Detweiler G, Wells J, Varel V, et al. Methane emissions by goats consuming sericea lespedeza at different feeding frequencies. Anim Feed Sci Technol. 2012;175:76-84.

110. Pal K, Patra AK, Sahoo A, Kumawat PK. Evaluation of several tropical tree leaves for methane production potential, degradability and rumen fermentation in vitro. Livest Sci. 2015;180:98-105.

111. Tavendale MH, Meagher LP, Pacheco D, Walker N, Attwood GT, Sivakumaran S. Methane production from in vitro rumen incubations with Lotus pedunculatus and Medicago sativa, and effects of extractable condensed tannin fractions on methanogenesis. Anim Feed Sci Technol. 2005;123:403-19.

112. Hatew B, Stringano E, Mueller-Harvey I, Hendriks W, Carbonero CH, Smith L, et al. Impact of variation in structure of condensed tannins from sainfoin (Onobrychis viciifolia) on in vitro ruminal methane production and fermentation characteristics. J Anim Physiol Anim Nutr. 2015;100:348-60.

113. Saminathan M, Sieo CC, Abdullah N, Wong CMVL, Ho YW. Effects of condensed tannin fractions of different molecular weights from a leucaena leucocephala hybrid on in vitro methane production and rumen fermentation. J Sci Food Agric. 2015;95:2742-9.

114. Saminathan M, Sieo CC, Gan HM, Abdullah N, Wong CMVL, Ho YW. Effects of condensed tannin fractions of different molecular weights on population and diversity of bovine rumen methanogenic archaea in vitro, as determined by high-throughput sequencing. Anim Feed Sci Technol. 2016; 216:146-60.

115. Oskoueian E, Abdullah N, Oskoueian A. Effects of flavonoids on rumen fermentation activity, methane production, and microbial population. BioMed Res Int. 2013;2013:8.

116. Becker PM, van Wikselaar PG, Franssen MCR, de Vos RCH, Hall RD, Beekwilder J. Evidence for a hydrogen-sink mechanism of (+)catechinmediated emission reduction of the ruminant greenhouse gas methane. Metabolomics. 2013;10:179-89.

117. Aemiro A, Hanada M, Umetsu K, Nishida T. The effect of sunphenon 30S-O on methane emission, nutrient intake, digestibility and rumen fermentation. Anim Feed Sci Technol. 2016;214:34-43.

118. Seradj A, Abecia L, Crespo J, Villalba D, Fondevila M, Balcells J. The effect of Bioflave ${ }^{\oplus}$ and its pure flavonoid components on in vitro fermentation parameters and methane production in rumen fluid from steers given high concentrate diets. Anim Feed Sci Technol. 2014;197:85-91.

119. Patra AK, Saxena J. The effect and mode of action of saponins on the microbial populations and fermentation in the rumen and ruminant production. Nutr Res Rev. 2009:22:204-19.

120. Patra AK, Yu Z. Effective reduction of enteric methane production by a combination of nitrate and saponin without adverse effect on feed degradability, fermentation, or bacterial and archaeal communities of the rumen. Bioresour Technol. 2013;148:352-60.

121. Belanche A, Pinloche E, Preskett D, Newbold CJ. Effects and mode of action of chitosan and ivy fruit saponins on the microbiome, fermentation and methanogenesis in the rumen simulation technique. FEMS Microbiol Ecol. 2016;92(1). doi: 10.1093/femsec/fiv160.

122. Cieslak A, Zmora P, Stochmal A, Pecio L, Oleszek W, Pers-Kamczyc E, et al. Rumen antimethanogenic effect of Saponaria officinalis $L$. phytochemicals in vitro. J Agric Sci. 2014;152:981-93.

123. Patra AK, Yu Z. Effects of vanillin, Quillaja saponin, and essential oils on in vitro fermentation and protein-degrading microorganisms of the rumen. Appl Microbiol Biotechnol. 2014;98:897-905.

124. Patra A, Stiverson J, Yu Z. Effects of Quillaja and Yucca saponins on communities and select populations of rumen bacteria and archaea, and fermentation in vitro. J Appl Microbiol. 2012;113:1329-40.

125. Ramírez-Restrepo CA, Tan C, O'Neill CJ, López-Villalobos N, Padmanabha J, Wang J, et al. Methane production, fermentation characteristics, and microbial profiles in the rumen of tropical cattle fed tea seed saponin supplementation. Anim Feed Sci Technol. 2016;216:58-67.

126. Patra AK, Saxena J. Dietary phytochemicals as rumen modifiers: A review of the effects on microbial populations. Antonie Leeuwenhoek. 2009;96:363-75.

127. Newbold CJ, Lassalas B, Jouany JP. The importance of methanogens associated with ciliate protozoa in ruminal methane production in vitro. Lett Appl Microbiol. 1995;21:230-4.

128. Calsamiglia S, Busquet M, Cardozo PW, Castillejos L, Ferret A. Invited review: Essential oils as modifiers of rumen microbial fermentation. J Dairy Sci. 2007; 90:2580-95

129. Patra AK. Effects of essential oils on rumen fermentation, microbial ecology and ruminant production. Asian J Anim Vet Adv. 2011;6:416-28. 
130. Cobellis G, Trabalza-Marinucci M, Yu Z. Critical evaluation of essential oils as rumen modifiers in ruminant nutrition: A review. Sci Total Environ. 2016; 545-546:556-68

131. Patra AK. Meta-analyses of effects of phytochemicals on digestibility and rumen fermentation characteristics associated with methanogenesis. J Sci Food Agric. 2010;90:2700-8.

132. Durmic Z, Moate PJ, Eckard R, Revell DK, Williams R, Vercoe PE. In vitro screening of selected feed additives, plant essential oils and plant extracts for rumen methane mitigation. J Sci Food Agric. 2014;94:1191-6.

133. Cobellis G, Trabalza-Marinucci M, Marcotullio MC, Yu Z. Evaluation of different essential oils in modulating methane and ammonia production, rumen fermentation, and rumen bacteria in vitro. Anim Feed Sci Technol. 2016;215:25-36

134. Khorrami B, Vakili A, Mesgaran MD, Klevenhusen F. Thyme and cinnamon essential oils: Potential alternatives for monensin as a rumen modifier in beef production systems. Anim Feed Sci Technol. 2015;200:8-16.

135. Tomkins NW, Denman SE, Pilajun R, Wanapat M, McSweeney CS, Elliott R. Manipulating rumen fermentation and methanogenesis using an essential oil and monensin in beef cattle fed a tropical grass hay. Anim Feed Sci Technol. 2015;200:25-34.

136. Leng $R$. The potential of feeding nitrate to reduce enteric methane production in ruminants. A Report to the Departmernt of Climate Change Commonwealth Government of Australia ACT Canberra Australia. 2008. http://www.penambulbooks.com. Accessed Aug 2016.

137. Lin M, Schaefer D, Zhao G, Meng Q. Effects of nitrate adaptation by rumen inocula donors and substrate fiber proportion on in vitro nitrate disappearance, methanogenesis, and rumen fermentation acid. Animal. 2013;7:1099-105.

138. Nolan J, Hegarty R, Hegarty J, Godwin I, Woodgate R. Effects of dietary nitrate on fermentation, methane production and digesta kinetics in sheep. Anim Prod Sci. 2010;50:801-6.

139. Van Zijderveld S, Gerrits W, Dijkstra J, Newbold J, Hulshof R, Perdok H. Persistency of methane mitigation by dietary nitrate supplementation in dairy cows. J Dairy Sci. 2011;94:4028-38.

140. Li L, Davis J, Nolan J, Hegarty R. An initial investigation on rumen fermentation pattern and methane emission of sheep offered diets containing urea or nitrate as the nitrogen source. Anim Prod Sci. 2012;52:653-8.

141. Newbold J, Van Zijderveld S, Hulshof R, Fokkink W, Leng R, Terencio P, et al. The effect of incremental levels of dietary nitrate on methane emissions in Holstein steers and performance in Nelore bulls. J Anim Sci. 2014;92:5032-40.

142. Van Zijderveld S, Gerrits W, Apajalahti J, Newbold J, Dijkstra J, Leng R, et al. Nitrate and sulfate: Effective alternative hydrogen sinks for mitigation of ruminal methane production in sheep. J Dairy Sci. 2010;93:5856-66.

143. Yang C, Rooke JA, Cabeza I, Wallace RJ. Nitrate and inhibition of ruminal methanogenesis: Microbial ecology, obstacles, and opportunities for lowering methane emissions from ruminant livestock. Front Microbiol. 2016; 7:132.

144. Asanuma N, Yokoyama S, Hino T. Effects of nitrate addition to a diet on fermentation and microbial populations in the rumen of goats, with special reference to Selenomonas ruminantium having the ability to reduce nitrate and nitrite. Anim Sci J. 2015:86:378-84.

145. Kandylis K. Toxicology of sulfur in ruminants: Review. J Dairy Sci. 1984;67 2179-87.

146. Latham EA, Anderson RC, Pinchak WE, Nisbet DJ. Insights on alterations to the rumen ecosystem by nitrate and nitrocompounds. Front Microbiol. 2016;7:228.

147. Anderson R, Carstens G, Miller R, Callaway T, Schultz C, Edrington T, et al. Effect of oral nitroethane and 2-nitropropanol administration on methaneproducing activity and volatile fatty acid production in the ovine rumen. Bioresour Technol. 2006;97:2421-6.

148. Anderson RC, Krueger NA, Stanton TB, Callaway TR, Edrington TS, Harvey RB, et al. Effects of select nitrocompounds on in vitro ruminal fermentation during conditions of limiting or excess added reductant. Bioresour Technol. 2008;99:8655-61.

149. Gutierrez-Bañuelos H, Anderson RC, Carstens GE, Slay LJ, Ramlachan N, Horrocks SM, et al. Zoonotic bacterial populations, gut fermentation characteristics and methane production in feedlot steers during oral nitroethane treatment and after the feeding of an experimental chlorate product. Anaerobe. 2007;13:21-31.

150. Kolver E, Aspin P, Jarvis G, Elborough K, Roche J, editors. Fumarate reduces methane production from pasture fermented in continuous culture. Proc New Zealand Soc Anim Prod, Vol 64, Hamilton, 155-159, 2004.
151. Pal K, Patra AK, Sahoo A, Mandal GP. Effect of nitrate and fumarate in Prosopis cineraria and Ailanthus excelsa leaves-based diets on methane production and rumen fermentation. Small Ruminant Res. 2014;121:168-74.

152. Foley P, Kenny D, Callan J, Boland T, O'mara F. Effect of malic acid supplementation on feed intake, methane emission, and rumen fermentation in beef cattle. J Anim Sci. 2009:87:1048-57.

153. Yang C, Mao S, Long L, Zhu W. Effect of disodium fumarate on microbial abundance, ruminal fermentation and methane emission in goats under different forage: Concentrate ratios. Animal. 2012;6:1788-94.

154. Reis L, Chaves A, Williams S, Moate P. Comparison of enantiomers of organic acids for their effects on methane production in vitro. Anim Prod Sci. 2014;54:1345-9.

155. Ungerfeld EM, Rust SR, Burnett R. Use of some novel alternative electron sinks to inhibit ruminal methanogenesis. Reprod Nutr Dev. 2003;43:189-202.

156. Beauchemin KA, McGinn SM. Methane emissions from beef cattle: Effects of fumaric acid, essential oil, and canola oil. J Anim Sci. 2006;84:1489-96.

157. Carro MD, Ungerfeld EM. Utilization of organic acids to manipulate ruminal fermentation and improve ruminant productivity. In: Puniya KA, Singh R, Kamra ND, editors. Rumen microbiology: From evolution to revolution. New Delhi: Springer India; 2015. p. 177-97.

158. Tedeschi LO, Fox DG, Tylutki TP. Potential environmental benefits of ionophores in ruminant diets. J Environ Qual. 2003;32:1591-602.

159. Chalupa W. 1 - Manipulation of rumen fermentation. In: Haresign W and Cole DJA editors. Recent developments in ruminant nutrition - 2: Butterworth-Heinemann: London. 1988. p. 1-18.

160. Kim M, Eastridge M, Yu Z. Investigation of ruminal bacterial diversity in dairy cattle fed supplementary monensin alone and in combination with fat, using pyrosequencing analysis. Can J Microbiol. 2013;60:65-71.

161. Kim M, Felix TL, Loerch SC, Yu Z. Effect of haylage and monensin supplementation on ruminal bacterial communities of feedlot cattle. Curr Microbiol. 2014;69:169-75.

162. Guan H, Wittenberg K, Ominski K, Krause D. Efficacy of ionophores in cattle diets for mitigation of enteric methane. J Anim Sci. 2006;84:1896-906.

163. van Vugt SJ, Waghorn GC, Clark DA, Woodward SL. Impact of monensin on methane production and performance of cows fed forage diets. Proc New Zealand Society of Anim Product. Vol 65, Christchurch, 362-366, 2005.

164. Odongo NE, Bagg R, Vessie G, Dick P, Or-Rashid MM, Hook SE, et al. Longterm effects of feeding monensin on methane production in lactating dairy cows. J Dairy Sci. 2007;90:1781-8.

165. Appuhamy JRN, Strathe A, Jayasundara S, Wagner-Riddle C, Dijkstra J, France $J$, et al. Anti-methanogenic effects of monensin in dairy and beef cattle: $A$ meta-analysis. J Dairy Sci. 2013;96:5161-73.

166. Lee SS, Hsu J-T, Mantovani HC, Russell JB. The effect of bovicin HC5, a bacteriocin from Streptococcus bovis HC5, on ruminal methane production in vitro. FEMS Microbiol Lett. 2002;217:51-5.

167. Sar C, Mwenya B, Pen B, Morikawa R, Takaura K, Kobayashi T, et al. Effect of nisin on ruminal methane production and nitrate/nitrite reduction in vitro. Crop Pasture Sci. 2005;56:803-10.

168. Patra AK. Enteric methane mitigation technologies for ruminant livestock: A synthesis of current research and future directions. Environ Monit Assess. 2012;184:1929-52.

169. Patra AK, Yu Z. Combinations of nitrate, saponin, and sulfate additively reduce methane production by rumen cultures in vitro while not adversely affecting feed digestion, fermentation or microbial communities. Bioresour Technol. 2014:155:129-35.

170. Narvaez N, Wang Y, McAllister T. Effects of extracts of Humulus lupulus (hops) and Yucca schidigera applied alone or in combination with monensin on rumen fermentation and microbial populations in vitro. J Sci Food Agric. 2013;93:2517-22.

171. Guyader J, Eugène M, Meunier B, Doreau M, Morgavi D, Silberberg M, et al. Additive methane-mitigating effect between linseed oil and nitrate fed to cattle. J Anim Sci. 2015:93:3564-77.

172. Tokura M, Ushida K, Miyazaki K, Kojima Y. Methanogens associated with rumen ciliates. FEMS Microbiol Ecol. 1997:22:137-43.

173. Mosoni P, Martin C, Forano E, Morgavi DP. Long-term defaunation increases the abundance of cellulolytic ruminococci and methanogens but does not affect the bacterial and methanogen diversity in the rumen of sheep. J Anim Sci. 2011:89:783-91.

174. Morgavi DP, Martin C, Jouany JP, Ranilla MJ. Rumen protozoa and methanogenesis: Not a simple cause-effect relationship. Br J Nutr. 2012;107:388-97. 
175. Tymensen LD, Beauchemin KA, McAllister TA. Structures of free-living and protozoa-associated methanogen communities in the bovine rumen differ according to comparative analysis of 165 rRNA and mcra genes. Microbiol. 2012;158:1808-17.

176. Tothova T, Piknova M, Kisidayova S, Javorsky P, Pristas P. Distinctive archaebacterial species associated with anaerobic rumen protozoan entodinium caudatum. Folia Microbiol (Praha). 2008:53:259-62.

177. Jukes TH, Cantor CR. Chapter 24 - Evolution of protein molecules. IN: Munro HN, editor. Mammalian protein metabolism. New York, NY: Academic Press, 1969: p. 21-132.

178. Tamura K, Stecher G, Peterson D, Filipski A, Kumar S. MEGA6: Molecular Evolutionary Genetics Analysis Version 6.0. Mol Biol Evol. 2013;30:2725-9.

Submit your next manuscript to BioMed Central and we will help you at every step:

- We accept pre-submission inquiries

- Our selector tool helps you to find the most relevant journal

- We provide round the clock customer support

- Convenient online submission

- Thorough peer review

- Inclusion in PubMed and all major indexing services

- Maximum visibility for your research

Submit your manuscript at www.biomedcentral.com/submit 